\title{
LA INFANCIA ABANDONADA EN PONTEVEDRA, 1872-1931
}

\section{Abandoned childhood in Pontevedra, 1872-1931}

\author{
Ana María Rodríguez Martín
}

Universidad de Barcelona

Recibido: $16 / 03 / 20$

Aceptado: 01/07/20

\begin{abstract}
Resumen
El objetivo de este artículo es el análisis de las causas del abandono de niños en la Inclusa de Pontevedra y el estudio de las formas de su recuperación por parte de sus madres o sus familiares. Para ello se establecen las condiciones en las que vivían la mayoría de las mujeres y las ayudas a la maternidad con las que podían contar. Además, se traza la postura de la Inclusa ante los diversos tipos de reclamación de sus asilados por parte de sus familiares.
\end{abstract}

\section{Palabras clave}

Infancia, expósitos, madres, ayudas a la maternidad, inclusas, nodrizas sin retribución, Pontevedra, siglos XIX y XX

\section{Abstract}

This article analyses the causes of children abandonment at the Pontevedra Foundling Hospital as well as the mothers (or other relatives) strategies to recover their children. In order to do this, we study the mothers' conditions of life and the aid and support available to them. Moreover, we describe the Foundling Hospital attitude towards the different sorts of claims made by the foundlings or their relatives.

\section{Key words}

Childhood, foundlings, mothers, maternity aid, Foundling Hospital, unpaid wet-nurses, Pontevedra, XIX and XX centuries 


\section{Introducción ${ }^{1}$}

El Reglamento del 14-5-1852 que desarrollaba la Ley de Beneficencia de 1849 establecía que, con carácter provincial, hubiera una casa de maternidad y expósitos en cada capital de provincia que fuera posible ${ }^{2}$. En Pontevedra, aunque no llegó a construirse una maternidad ${ }^{3}$, la Inclusa empezó a funcionar el 1 de julio de $1872^{4}$. Su objetivo, según su reglamento de 1878, era el acogimiento de expósitos ${ }^{5}$ entre cero y 7 años de edad ${ }^{6}$, aunque desde el año siguiente a su creación admitió también a hijos naturales ${ }^{7}$ e hijos de legítimo matrimonio, siempre que se encontraran desamparados y desvalidos, y que fueran naturales de la provincia o que sus padres llevaran varios años de residencia en ella ${ }^{8}$.

La Inclusa de Pontevedra estaba financiada en su totalidad por la Diputación Provincial, y fue dirigida desde 1878 hasta 1925 por la Comisión de Diputados provinciales 9 . Después de ese año todas las decisiones las tomó la Comisión Provincial Permanente. La Iglesia tuvo un papel importante en la Inclusa porque de la organización interna, desde 1878, se encargaron las Hijas de la Caridad de San Vicente de Paúl ${ }^{10}$ y porque siempre hubo una capilla y un capellán.

Las tres ubicaciones sucesivas de la Inclusa fueron en el convento de Santa Clara hasta 1876, luego en el exconvento de San Francisco hasta 1903 y, a partir de ese año, en el de los jesuitas ${ }^{11}$. La Inclusa solo ocupaba una pequeña parte de estos

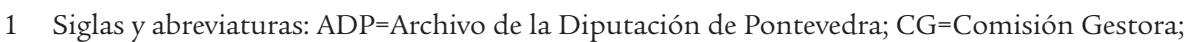
$\mathrm{CPP}=$ Comisión Provincial Permanente; u.i.=unidad de instalación.

2 Reglamento del 14-5-1852 para la ejecución de la Ley de Beneficencia del 20-6-1849, art. 6 y 38. MaZa Zorrilla, E. (1987): 232 y 236.

3 Creemos que la Maternidad no llegó a crearse por falta de voluntad de la Diputación, que se reflejó también en la creación de la Inclusa, que no empezó a funcionar hasta 20 años después del Reglamento de 1852 ya citado. Es verdad que la Diputación Provincial concedía subvenciones a instituciones benéficas privadas, pero no se hacía cargo de ellas, ni organizativa ni financieramente. En el Hospicio de Pontevedra, creado en 1853 por la Asociación Benéfica de Señoras, la Diputación no se implicó en su dirección hasta 1878, en este caso junto con el Ayuntamiento y dos párrocos representantes del arzobispado de Santiago. RodríGuez MarTín, A.M. (2015): 129.

4 ADP, u.i. 993.

5 Los niños expósitos eran los que habían sido abandonados, expuestos o confiados a un establecimiento de beneficencia. Diccionario de la lengua española (2004): 1.023.

6 ADP, u.i. 984.

7 Los hijos naturales, que eran ilegítimos, habían nacido de padres que, en el momento de su concepción, hubieran podido casarse por no existir impedimento legal alguno para ello. CáMARA ÁlLVAREZ, M. de la (1975): 10-11.

8 En las inclusas española se solían exigir diez años de residencia. Puig y Alfonso, F. (1927): 267.

9 Anteriormente, de 1872 a 1878, la dirección la ejerció una comisión formada por el presidente de la Diputación, un interventor y la presidenta de la de la Asociación de Señoras de Beneficencia. ADP, u.i. 14.721/1.

10 Rodríguez MarTín, A. M. (2008): 355-356.

11 ADP, u.i. 993. Garnelo Mariñas, E. (1988): 145. 
edificios, porque albergaba a pocas personas: las amas internas fluctuaban entre 2 y 6 , los ingresados se entregaban muy pronto a lactancia externa, y solamente había 2 o 3 Hijas de la Caridad y un portero ${ }^{12}$. Como de la limpieza de la sala de lactantes, así como de la de las cunas y las ropas de los niños, se encargaban las nodrizas internas, solo había una criada. Tanto estas amas, como las externas, cobraban salarios muy bajos, por lo que la Inclusa se encontró, a lo largo del período que examinamos, con el problema de que no se presentaba el número suficiente de mujeres para ejercer este trabajo ${ }^{13}$. Frente a ello, el número de ingresados anualmente en la Inclusa de Pontevedra fue aumentando desde su creación hasta llegar a su máximo, 189, en 1915. Después, descendió lentamente hasta los 111 en 1924. Como al año siguiente se cerró el torno y se estableció un límite a las admisiones, los ingresos bajaron de forma drástica siendo tan solo de 29 en $1930^{14}$.

En la Inclusa de Pontevedra el protocolo de entrada de los niños era el siguiente: primero se anotaban en el libro de registro de entradas correspondiente, en el que también se copiaba el contenido textual de cualquier nota o trozo de papel que portasen. En esas notas solía haber alguna información sobre la criatura que se dejaba en el torno. Podía ser la fecha de nacimiento o de exposición, el nombre y apellidos que se deseaba que se le impusieran, las razones por las que se abandonaba o la promesa de su recuperación. También se informaba si el niño había recibido o no el bautismo. Posteriormente, el recién ingresado quedaba al cuidado de las nodrizas internas $y$, pasado un tiempo, era dado a un ama externa, generalmente rural, que recibía una paga mensual de la Inclusa por hacerse cargo de él. Si por alguna razón decidía devolverlo, la Inclusa lo entregaba a otra nodriza, por lo que en los locales del establecimiento benéfico no solía haber muchos niños. Cuando los menores llegaban a los 7 años de edad, las amas ya no cobraban por ellos y podían elegir entre quedárselos indefinidamente o devolverlos a la Inclusa desde donde ingresarían en el Hospicio.

En la provincia de Pontevedra había dos inclusas más. La de Tui estaba unida al hospital de esta localidad, se encargaba de ella una Junta de Patronos formada por particulares y canónigos, presidida por el obispo de Tui, y de la Diputación Provincial solo recibía una subvención. En este establecimiento benéfico ingresaban pocos niños, de 1872 a 1883 solo 250 , y los locales que sucesivamente fue ocupando eran muy reducidos, poco saludables y faltos de higiene, hasta que en

12 Sesión de la Comisión de Diputados, 27-6-1904. ADP, u.i. 14.721/1.

13 Rodríguez Martín, A. M. (2003): 190. Sesiones de la Comisión de Diputados, 20-9-1906, $27-$ 6-1904, 18-9-1910, 6-12-1911, 18-9-1912 y 25-6-1918. ADP, u.i. 14.721/1. Sesión de la CPP, 9-4-1927. ADP, u.i. 13.152, pág. 70.

14 ADP, u.i. 14.721/2-14.731/1. 
1923 se inauguró un nuevo edificio para inclusa y hospital ${ }^{15}$. La otra inclusa de la provincia era la de Vigo, llamada Casa de Caridad-Hogar San José, que estaba atendida por las Hermanas de la Caridad y socorría a expósitos y pobres de solemnidad. Había sido creada en 1839 por el Ayuntamiento de Vigo en el exconvento de San Francisco de esa ciudad con el nombre de Casa de Beneficencia, y creemos que dejó de albergar expósitos cuando se creó la Inclusa de Pontevedra porque en los libros de ingresos de esta institución provincial constan ya en 1881 y 1884, al igual que en años posteriores, niños que habían sido expuestos en Lavadores y en Vigo ${ }^{16}$. Además, en 1894, una guía de la provincia afirmaba que la Casa de Caridad no albergaba expósitos ${ }^{17}$ y, en 1897, el reglamento de esta institución detallaba que solo acogía a menores a partir de los seis años de edad ${ }^{18}$.

Respecto a la Inclusa de Pontevedra, en este artículo se intentan establecer las causas por las que ingresaban los niños y por las que, en algunos casos, eran recuperados por sus madres y familiares. Para ello, y a partir de bibliografía especializada, prensa de la época, memorias de la Junta Provincial de Beneficencia de Pontevedra y la revista Pro-Infantia de la Junta Superior de Protección a la Infancia, analizamos la situación de las mujeres gallegas y españolas, su nivel de instrucción, sus ocupaciones, su pobreza, las soluciones de las que disponían ante un embarazo no deseado, y las ayudas a la maternidad con las que podían contar, todo ello durante la segunda mitad del siglo XIX y primer tercio del XX.

Ante el problema de un hijo que no se podía o no se quería lactar y cuidar, una solución eran las inclusas. Mediante el estudio de los libros de ingresos de la de Pontevedra hemos establecido el número de niños entrados anualmente en el período que va de 1872, año de creación de la institución benéfica, hasta 1931, cuando comienza la II República. Posteriormente, hemos calculado el número de supervivientes y el de los recuperados por sus progenitores y familiares. Los expedientes personales de cada asilado nos han permitido, además, analizar los cauces que se seguían en estas recuperaciones. El problema es que la colección de estos expedientes no está completa, sobre todo la del siglo XIX.

La postura de la Inclusa ante las solicitudes de entrega de sus acogidos la hemos estudiado a partir de los libros de actas de la Comisión Provincial Permanente y de la Comisión Gestora de la Diputación Provincial de Pontevedra, de los legajos que

15 Bouzón gallego, A. (2001): 361-366. "Los nuevos presupuestos”, El Progreso, 5.734 (5-71925). "Comisión provincial", La Correspondencia gallega, 5.237 (24-7-1907), disponible en <http://biblioteca.galiciana.gal>. La mayoría de los periódicos pontevedreses de la época están sin paginar.

16 ADP, u.i. 961.

17 Guia general de la provincia de Pontevedra (1894): 36.

18 Mateo Álvarez, J. L. (2002): 62-73. 
contienen la correspondencia de la Inclusa con párrocos, autoridades y organismos varios, $y$ de los expedientes personales de los incluseros ${ }^{19}$. Toda esta documentación, además, nos ha permitido ver las características de las madres, padres y familiares que reclamaban a estos niños, y las razones que alegaban para justificar el haber dejado a sus hijos en la Institución y también para, posteriormente, recuperarlos. La información aportada por esta documentación podría haber sido completada con la suministrada por la prensa, pero la Inclusa apenas era citada en ella ${ }^{20}$. La poca importancia que se le concedía podemos verla en dos años importantes para este establecimiento benéfico. El primero fue 1918, cuando se produjo la inspección de la Junta Provincial de Protección a la Infancia ${ }^{21}$. De sus resultados solo se informó un día, y en tres de los periódicos la fuente era la misma Junta Provincial ${ }^{22}$. El segundo año fue 1925, cuando se cerró el torno y se estableció un número muy limitado de ingresos. De este tema solo se ocuparon un día cada uno de los tres periódicos consultados $^{23}$. Mientras, en el mismo año, el aniversario y a la imposición de la Gran Cruz de Beneficencia a Sor Rafael Echarte, superiora de las Hijas de la Caridad en la Inclusa y el Hospicio, mereció información durante siete días ${ }^{24}$.

\section{La situación de las mujeres y la protección de la maternidad en la segunda mitad del s. XIX y primer tercio del XX}

En la segunda mitad del siglo XIX, gran parte de la población vivía en el umbral de la pobreza y circunstancias negativas, como una enfermedad o la falta de trabajo, la abocaba a la miseria, dado que no existía un sistema de previsión o de seguridad

19 En todo el artículo se ha respetado la redacción y la ortografía original de las notas y las instancias redactadas por las madres, padres o familiares que recogieron a niños de la Inclusa de Pontevedra.

20 Las pocas veces que la Inclusa de Pontevedra aparecía en la prensa era por información suministrada por la propia Diputación relativa al ingreso de algún niño o de obras realizadas en el establecimiento benéfico. Otras veces era el aviso de pago a las nodrizas externas.

21 Los porcentajes de mortalidad de la Inclusa de Madrid aparecidos en la Memoria del Cuerpo Médico de la Beneficencia Provincial de esa provincia, en 1918, causaron una gran polémica en la prensa. Su consecuencia fue la Real Orden del 21-6-1918 en la que el Consejo Superior de Protección a la Infancia instaba a las Juntas Provinciales de Protección a la Infancia a realizar una visita de inspección a las inclusas de su provincia. Revuelta Eugercios, B. (2011): 212-215.

22 Periódicos revisados: La Libertad, El Progreso y El Tea, disponibles en <http://biblioteca. galiciana.gal>, y El Pueblo. Órgano del Partido Republicano.

23 Periódicos: La Libertad, El Progreso y El Tea, disponibles en <http://biblioteca.galiciana. gal>.

24 Periódico revisado: El Progreso, disponible en 〈http://biblioteca.galiciana.gal>. Además, "Homenaje a Sor Rafaela”, El Diario de Pontevedra, 12.219 (2-9-1925). 
social ${ }^{25}$. La mayoría de las mujeres, tanto las casadas que podían contar con el salario de un marido, como las solteras o viudas, vivía también en malas condiciones, aunque trabajasen fuera de casa y contasen con un jornal propio ${ }^{26}$. A principios del siglo XX la situación no había mejorado. En España, en 1905, tenían la calificación oficial de pobres 813.815 familias, es decir, 3.250 .000 personas, el 17,49\% del censo total de la población. Si a este grupo le sumamos los que estaban en el umbral de la pobreza, los marginados y los ingresados en instituciones benéficas, el círculo se amplía. En la provincia de Pontevedra, según estadísticas oficiales, en ese año de 1905 había 28.809 familias pobres ${ }^{27}$, que equivalían a 119.236 personas del total provincial, que eran $457.262^{28}$. Ante esta pobreza generalizada y permanente el Estado empezó a actuar fomentando la previsión y el ahorro para que la vejez, un accidente de trabajo o la maternidad no empujaran a los asalariados a la miseria. Los trabajadores gallegos, en su mayoría agrícolas, quedaron al margen de esta nueva política del Estado. Además, los centros benéficos, las ayudas y la atención domiciliaria se ubicaban en las ciudades, aun siendo rural la mayoría de la población gallega ${ }^{29}$. En este contexto, en los apartados que siguen veremos, tanto en Galicia como en el resto de España, las circunstancias particulares que agravaban la pobreza femenina, la deshonra que acarreaba un embarazo fuera del matrimonio, la difícil conciliación de maternidad y trabajo, y las ayudas que las madres pobres podían recibir. Todo ello facilitará el entendimiento de las razones de los abandonos y de las pocas recuperaciones de los niños dependientes de las inclusas y, más concretamente, de la de Pontevedra.

\subsection{La educación femenina}

A pesar de que la Ley de Instrucción Pública de 1857 había implantado la gratuidad y obligatoriedad de la enseñanza primaria para los niños y niñas de 6 a 9 años, en Galicia y en 1885 , todavía no había las escuelas que se necesitaban y muchas de las existentes estaban mal equipadas. Además, el absentismo escolar era elevado debido al trabajo infantil, a la distancia hasta el centro escolar y, en lo que se refiere a las niñas, a su dedicación a las labores domésticas ${ }^{30}$. La consecuencia es que durante toda la segunda mitad del siglo XIX, en Galicia, al igual que en el resto de España,

25 Trinidad Fernández, P. (1990): 104-105.

26 Arenal, C. (1974): 84.

27 La crisis de finales del siglo XIX colocó a Galicia en peor posición respecto al resto de España en el nivel de renta. Alonso Álvarez, L. (2005): 41-45, 53-54 y 72-73. Rodríguez Galdo, M. X. (1981): 129-134.

28 Maza Zorrilla, E. (1999): 15-16 y 208.

29 Vilar Rodríguez, M. (2007): 196.

30 Varela Iglesias, M. (2013): 44-46. 
el analfabetismo era muy elevado, el 72,63\% en 1887, pero si tenemos en cuenta solo al femenino, llegaba al 89,35\% ${ }^{31}$ y aunque en 1900 ya había disminuido, todavía seguía siendo notablemente superior al masculino. Esa diferencia se debía a que la educación de las niñas era considerada algo secundario, puesto que el papel que la sociedad reservaba a las mujeres era el de engendrar hijos, cuidarlos para que no fallecieran y transmitirles una serie de valores ${ }^{32}$. Por todo ello, las menores seguían cursando algunas materias diferentes a las de los varones, y muchas niñas de las capas más pobres padecían una escolarización deficiente ${ }^{33}$. No obstante, el tema de la educación comenzó a preocupar cada vez más a sectores amplios de la sociedad. Su reflejo fue la Ley del 23-6-1909, que estableció la escolarización obligatoria hasta los 12 años y que provocó, en las primeras décadas del siglo XX, un descenso del analfabetismo femenino en Galicia ${ }^{34}$ y también en el resto de España.

Respecto a la enseñanza secundaria, en la segunda mitad del siglo XIX, muy pocos jóvenes la cursaban, y de ellos la inmensa mayoría eran varones ${ }^{35}$. Aunque el número de las matriculadas gallegas y españolas fue creciendo lentamente en las primeras décadas del siglo XX, todavía continuaba siendo muy bajo ${ }^{36}$. Por su parte, entre el alumnado universitario, la presencia femenina era mínima. A pesar de que la Real Orden del 8-3-1910 reconoció el derecho de las mujeres a matricularse libremente en los centros oficiales, a finales de la segunda década del siglo XX ellas tan solo eran el $5 \%$ del total del alumnado ${ }^{37}$, y aunque ese porcentaje fue creciendo, lo hizo muy lentamente, como en la Universidad de Santiago de Compostela ${ }^{38}$.

\subsection{El trabajo de las mujeres}

En el último cuarto del siglo XIX se seguía considerando que el destino de la mujer era el matrimonio y, sobre todo, la maternidad, y que el ámbito femenino debía ser el doméstico ${ }^{39}$. Pero estos postulados no se hacían realidad entre las mujeres pobres porque ellas trabajaban mayoritariamente, aunque en los censos nacionales y en los padrones municipales la actividad femenina estuviera subregistrada al tener en cuenta solo el trabajo extradoméstico y asalariado y no contabilizar el que se desarrollaba en sectores informales, como la venta ambulante y el trabajo a domi-

31 CAstro, X. (2007): 170 y 174.

32 Benso Calvo, C. y Cid Galante, R.M. (2011 b): 192-193.

33 Ballarín Domingo, P. (2001): 45, 49, 136 y 149.

34 Benso Calvo, C. y Cid Galante, R.M. (2011 a): 48-50.

35 Амо del Amo, M.C. (2009): 14.

36 Benso Calvo, C. y Cid Galante, R.M. (2011a): 52.

37 Flecha García, C. (1996): 32-36 y 77-95.

38 Vázquez Ramil, R. (2012): 187.

39 Morata Marco, E. V. (2010): 347 y 356. 
cilio, o el realizado en la finca agrícola familiar ${ }^{40}$. En el campo, solo los cabezas de familia eran considerados agricultores, a pesar de que muchas mujeres ayudaban intensamente a sus padres o maridos, como ocurría en Galicia, donde, incluso, muchas veces ellas solas realizaban todas las faenas agrícolas, dada la fuerte emigración masculina y la gran proporción de marineros existentes. También muchas mujeres se dedicaban a la venta de sus excedentes de huevos, queso y jamones en mercados semanales o ferias, al igual que las esposas de los marineros vendían marisco y pescado ${ }^{41}$. Además, había un sector casi totalmente femenino, el servicio doméstico. Aunque el desarrollo comercial e industrial del siglo XIX favoreció que más jóvenes solteras trabajasen en el la industria y los servicios, tanto en Galicia como en el resto de España, el proceso de incorporación femenino al trabajo extradoméstico asalariado fue lento ${ }^{42}$.

Ya en las primeras décadas del siglo XX se diversificaron los sectores en los que laboraban las mujeres, aunque siempre en las categorías más bajas, y la legislación permitió su acceso al ejercicio de todas las profesiones relacionadas con el Ministerio de Instrucción y al trabajo en organismos públicos a nivel de auxiliar ${ }^{43}$. En Galicia, a pesar de que oficialmente un alto porcentaje de mujeres no tenía una ocupación reconocida y otro porcentaje todavía mayor se cuidaba de su hogar ${ }^{44}$, la realidad es que la mayoría trabajaba dentro y fuera de su casa, y aunque decreció el grupo más importante en el sector terciario, el de las sirvientas, aumentó el de las trabajadoras en la industria y en la administración pública ${ }^{45}$. En las conserveras de las Rías Bajas, y especialmente de Vigo, había muchas mujeres ocupadas, pero de forma temporal y con un salario más bajo que el de los hombres ${ }^{46}$.

\subsection{La maternidad}

En la segunda mitad del siglo XIX se consideraba que toda mujer casada debía cumplir la misión que la naturaleza le había otorgado, que era engendrar y cuidar a sus hijos. La Iglesia católica, por su lado, solo permitía como control de natalidad la abstinencia. La consecuencia era, tanto entre las casadas como entre las solteras, que los embarazos no deseados eran muy numerosos y, en algunos casos, finaliza-

40 Borderías, C. y Pérez- Fuentes, P. (2009): 272-279.

41 Rodríguez Labandeira, J. (1994): 260-261. Pernas Oroza, H. (2011): 57-63.

42 Amo del Amo, M.C. (2008): 438 y 543-546. Benso Calvo, C. y Cid Galante, R.M. (2011 a): 5961.

43 R.O. del 2-9-1910 y Estatuto de Funcionarios Públicos de 1918. Capel Martínez, R.M. (1986): 18.

44 Benso Calvo, C. y Cid Galante, R.M. (2011 a): 67-68.

45 Pernas Oroza, H. (2011): 64-66 y 71-82.

46 Muñoz Abeledo, L. (2012): 55-68. 
ban con un aborto o infanticidio, o con el abandono del recién nacido. El aborto estaba penado, tanto en el Código Penal de 1848 como en el de 1870, y la responsabilidad afectaba tanto a la mujer como a los médicos, comadronas o farmacéuticos que hubieran participado ${ }^{47}$.

En España, frente a un embarazo, una mujer soltera o viuda tenía vedado exigir responsabilidades al padre de su hijo y por eso podía encontrarse sola frente a la carga económica que suponía la crianza de un niño. Además, el Código Civil de 1889 establecía que el reconocimiento de un hijo natural podía hacerlo el padre, la madre o ambos, pero si solo lo hacía uno de ellos, no podía revelar el nombre de la persona con la que había tenido el niño ni expresar dato alguno que facilitara el conocimiento de su identidad ${ }^{48}$. Por tanto, un hombre podía eludir su responsabilidad, es decir, no dar a su hijo su apellido, no suministrar o pagar los alimentos que necesitaba y no dejarle la parte de la herencia que le correspondiera ${ }^{49}$. Algunas mujeres pobres, viéndose entonces solas con un recién nacido, pudieron optar por echarlo al torno de una inclusa ${ }^{50}$.

Como la actividad sexual estaba vinculada a concebir hijos legítimos, un embarazo sin matrimonio era una deshonra. Para evitarla, el Reglamento de 1852 que desarrollaba la Ley de Beneficencia de 1849 estableció la creación de maternidades en las capitales de provincia. Estas instituciones, que permitían parir secretamente y de la misma manera dejar al recién nacido en la inclusa correspondiente, tenían un notable matiz de encierro y corrección, puesto que en la mayoría de ellas las asiladas no podían recibir visitas ni de sus familiares, y en algunas se exigía la confesión y las prácticas religiosas eran obligatorias ${ }^{51}$. En Pontevedra, aunque el presupuesto de la Diputación consignase en 1925 una partida para la construcción de una maternidad ${ }^{52}$, ya vimos que no llegó a crearse.

En el primer tercio del siglo XX, el modelo de mujer cambia para adaptarse a las nuevas circunstancias políticas, sociales y económicas. En la creación de este modelo colaboraron los médicos, entre los que destacó Gregorio Marañón, que defendía la igual valoración social de ambos sexos, aunque con diferentes cometidos, pues el más importante para el femenino era el de la maternidad, incompatible con un trabajo extradoméstico, a no ser que fuera absolutamente necesario para la subsisten-

47 NASH, M. (1994): 167.

48 Código civil español (1889): 156-158, art. 129 y 132.

49 Ibidem: 160, art. 134.

50 En Francia, en el siglo XIX, las mujeres que dejaban a sus hijos en las inclusas eran, en su inmensa mayoría, solteras y procedían de medios humildes. LaPLAige, D. (1989): 20.

51 Rodríguez Martín, A.M. (2010): 165-168.

52 “Los nuevos presupuestos de la Diputación”, El Diario de Pontevedra, 12.169 (4-7-1925), disponible en <http://biblioteca.galiciana.gal>. 
cia de la familia ${ }^{53}$. Esta concepción de la mujer eliminaba por completo la planificación familiar que, además, estaba mal considerada en la sociedad española y chocaba con la idea imperante de que era necesaria una gran población para el desarrollo económico del país ${ }^{54}$. En Galicia, el porcentaje de madres solteras era muy alto. La elevada emigración masculina, el desequilibrio de sexos y la consiguiente soltería femenina ${ }^{55}$ podrían ser las causas de que los hijos naturales fueran numerosos.

\subsection{Las ayudas a las madres}

En el último cuarto del siglo XIX, aunque muchos médicos sostenían que la biología determinaba que las madres debían necesariamente cuidar y amamantar a sus hijos, no se desarrolló una política de apoyo dirigida a las que querían hacerlo pero no podían debido a su pobreza, enfermedad o falta de leche. España, frente a algunos países europeos, iba atrasada en lo que respecta a la protección social ${ }^{56}$. Sin embargo, a partir de 1890, tras la reorganización de la Comisión de Reformas Sociales, se presentaron varios proyectos de ley, que luego se convertirían en leyes, que regularon las condiciones del trabajo y la previsión social. Además, se crearon el Instituto de Reformas Sociales y el Instituto Nacional de Previsión, que empezaron a funcionar en 1903 y 1908, respectivamente ${ }^{57}$. Ya en la segunda década del siglo XX, en Europa occidental, frente al descenso de la natalidad, la elevada mortalidad infantil y los numerosos abandonos de niños, los Estados comenzaron a tomar medidas protectoras de la maternidad ${ }^{58}$, referidas al permiso antes y después del parto, y a las prestaciones durante el mismo ${ }^{59}$.

En España, el Estado también empezó a dar respuesta a algunos problemas de las madres, como el de la imposibilidad de conciliar lactancia y trabajo extradoméstico. La ley de 13-3-1900 y un Real Decreto de 1902 establecieron para las mujeres una jornada de once horas, es decir, 66 horas semanales. Sin embargo, no se respetó este aspecto de la ley y, además, el permiso de maternidad que se había establecido en tres semanas después del parto, como conllevaba la pérdida del jornal, no era disfrutado por las trabajadoras pobres, que eran todas, prácticamente ${ }^{60}$. La ley citada, además, concedía media hora por la mañana y otra por la tarde, que

53 NASH, M. (2010): 27-28.

54 NASH, M. (2000): 700.

55 Pernas Oroza, H. (2011): 26-30.

56 El retraso era grande respecto a Alemania, pionera en este campo, y resultaba menor en comparación con Francia e Inglaterra. MAZA Zorrilla, E. (1987): 136-139.

57 Montero García, F. (1994): 418. Palacio Morena, J. I. (2004): 26.

58 Fuchs, G.R. (2003): 277-279.

59 Bоск, G. (2000): 457-462.

60 Nielfa Cristóbal, G. (2004): 138. 
no se descontarían del salario, a las madres con hijos lactantes. El Real Decreto de 21-8-1923 significó un paso más en la protección de la maternidad, porque estableció que las obreras afiliadas al Retiro Obrero cobrarían 50 pesetas por parto y contarían con asistencia médica ${ }^{61}$. Sin embargo, en Galicia, la alta temporalidad de las trabajadoras en la industria conservera, que dificultaba su cotización continuada, frenaba su generalización. También encontró resistencias en este grupo laboral la Ley del seguro de maternidad obligatorio, del 22-3-1929, porque la cuota se descontaba del salario ${ }^{62}$. Las beneficiarias de este seguro no solo eran trabajadoras industriales, comerciales y de la minería, sino también del sector agrícola y del trabajo a domicilio. A las ocupadas en el servicio doméstico no les alcanzó este seguro, que incluía un subsidio de lactancia de 5 pesetas a la semana, asistencia sanitaria durante el parto, y medicinas, análisis y material farmacéutico durante el embarazo y parto $^{63}$.

Frente a la falta de leche de bastantes madres causada por sus enfermedades, su pobreza y sus duras condiciones de vida y trabajo ${ }^{64}$, unas instituciones llamadas La Gota de Leche eran una solución porque suministraban leche de vaca a bajo precio, e incluso gratis, a las mujeres pobres. Este alimento se trataba, se embotellaba en biberones y, por último, se esterilizaba. Además, estas Gotas tenían un consultorio y divulgaban los cuidados que se debían tener con la higiene y la alimentación de los niños. En España, las primeras Gotas, fruto de la iniciativa de médicos y filántropos locales, y posteriormente también de los ayuntamientos, se crearon en Barcelona y Madrid, en los primeros años del siglo XX, y les siguieron las de otras ciudades ${ }^{65}$, algunas de ellas gallegas ${ }^{66}$. El éxito de alguna de estas instituciones fue notable: en San Sebastián, en 1908, la mortalidad de los asistidos de 0-2 años fue menor que la de la población de esa edad no asistida ${ }^{67}$. El problema era que, en ese año, en España, nada más había 15 Gotas de Leche en el total de capitales de provincia y solo 4 estaban en proyecto. El panorama, cinco años más tarde, era bastante parecido porque aunque se iban instalando algunas más en ciudades importantes, lo hacían de forma muy lenta ${ }^{68}$.

61 Espuny Tomás, M. J. (2010): 189-192.

62 Vilar Rodríguez, M. (2007): 185 y 193-194.

63 Valiente Hernández, C. (1996): 61.

64 Freire Lestón, X.V. (1992): 425. Castro, X. (2007): 371-375.

65 "Instituto Municipal de Puericultura", Pro-Infantia, 55 y 56 (1913): 326-327. "La Gota de Leche en Zaragoza”, Pro-Infantia, 46 (1913): 85-88.

66 "Noticias de Galicia”, La Correspondencia gallega, 6.617 y 6.934 (23-3-1912 y 16-4-1913, respectivamente). "De Galicia” y "Noticias”, El Progreso, 980 y 1.635, respectivamente (15-41913 y 5-6-1914), disponibles en <http://biblioteca.galiciana.gal>.

67 "La Gota de Leche", Pro-Infantia, 5 (1909): 224-225.

68 "España. Protección a la infancia”, Pro-Infantia, 58 (1910): 280. "Dispensario para los niños de pecho”, Pro-Infantia, 6 (1914): 156. 
La Gota de Leche de Vigo empezó a funcionar en $1915^{69}$. Esta institución, además de instruir a las madres en las normas de la Puericultura, les entregaba leche, ropas y medicamentos para sus hijos y, en 1930, si ellas no tenían lo necesario para alimentarse, les concedía un subsidio diario o bien les ofrecía comer en la Cocina Económica. En cuanto a los niños, se les controlaba médicamente cada mes y se les vacunaba $a^{70}$.

La Gota de Leche de Pontevedra, que nació en 1916, dependía del mismo organismo que la de Vigo, la Junta de Protección a la Infancia ${ }^{71}$, y proporcionaba los mismos servicios a las madres y a los menores atendidos, que solían ser alrededor de unos veinticinco ${ }^{72}$. Aunque en 1918 esta institución todavía funcionaba, creemos que posteriormente dejó de hacerlo porque en 1924 y 1925 la Diputación y la Inspección de Sanidad, respectivamente, proyectaron instalar una Gota de leche en la ciudad de Pontevedra ${ }^{73}$, pero no se hizo realidad hasta 1933 , como un anexo de la Inclusa Provincial dependiente de la Diputación ${ }^{74}$.

Respecto a las ayudas a la lactancia, sabemos que la Inclusa de Pontevedra concedió algunas ya en la segunda mitad del siglo XIX, como hacían otras instituciones similares españolas y europeas ${ }^{75}$. Su finalidad era reducir los abandonos de niños al permitir a las madres pobres poder pagar a una nodriza si no tenían leche o necesitaban continuar trabajando. La primera ayuda de la Inclusa de Pontevedra que hemos encontrado data de 1885 , y fue concedida al viudo de una mujer fallecida por el cólera que había dejado ocho hijos, el más pequeño de cuatro meses. El socorro consistió en 0,25 céntimos diarios para el pago de un ama de leche. Después, durante años, parece que no se concedieron más ayudas, cuestión que no resulta extraña puesto que en el caso que acabamos de ver la Comisión Provincial remarcó que ese socorro era algo excepcional, dado que el Reglamento de la Inclusa no lo autorizaba ${ }^{76}$. No obstante, en 1899 , recibió la misma ayuda una madre soltera, pobre y con una debilidad general que no le permitía amamantar a su niño y por ello lo estaba haciendo una vecina por caridad. En los años siguientes

69 "La beneficencia en Vigo", La Correspondencia gallega, 8.186 (6-11-1916). "Diputación Provincial”, El Tea, 19 (14-7-1925): 3, disponibles en <http://biblioteca.galiciana.gal>.

70 Álvarez Novoa, R. (1930): 155-156.

71 Junta Provincial de Beneficencia de Pontevedra (1926): 64.

72 "Junta de Protección a la Infancia", La Correspondencia gallega, 8.022 (23-5-1916), disponible en <http://biblioteca.galiciana.gal>. Reglamento provisional para el servicio... (1916): sin paginar.

73 “Acta de la Junta General del 14-9-1924", Boletín oficial del Colegio de Médicos de Pontevedra, 5, (1-12-1924): 6. "Una nota oficiosa de la Inspección de Sanidad y un comentario", El Progreso, 5.906 (25-11-1928), disponibles en <http://biblioteca.galiciana.gal〉.

74 Sesión de la CG, 9-11-1933. ADP, u.i. 13.160, pág. 148.

75 Knibiehler, Y. (2001): 370. Valverde Lamsfus, L. (1991): 1.178-1.181.

76 Sesión de la CPP, 10-9-1885. ADP u.i. 13.028, págs. 321-322. 
algunas mujeres percibieron estos socorros durante el período de lactancia de su hijo y, a veces, incluso, durante el de destete ${ }^{77}$. La última ayuda que encontramos fue concedida en 1929 a un jornalero viudo, padre de 7 niños, tres de ellos trillizos recién nacidos ${ }^{78}$.

Las madres que necesitaban trabajar después de haber dado a luz se encontraban con el problema de la ausencia o escasez de guarderías, llamadas entonces asilos o casas-cuna. Esta situación, según Concepción Arenal, tenía consecuencias graves para bastantes mujeres pobres, porque agravaba su situación,

...las atenciones imprescindibles hacen imposible el trabajo para un gran número de mujeres que tienen que cuidar niños pequeños. A unas las ha dejado viudas la muerte, otras pueden llamarse viudas del vicio o de la pasión, del criminal abandono de su marido, su seductor, o de su cómplice. Si la beneficencia pública o la caridad privada no abren asilos donde recoger estos pobres niños, es imposible que las madres trabajen y que no caigan en la mendicidad o en la prostitución ${ }^{79}$.

En algunos países europeos a mediados del siglo XIX ya existían casas-cuna ${ }^{80}$. En España, en las décadas finales del siglo XIX y a principios del siguiente, se fueron creando las primeras, que generalmente tenían carácter privado y solían estar atendidas por órdenes religiosas ${ }^{81}$. El problema era que estas instituciones solo funcionaban en las ciudades grandes y la demanda de plazas era muy superior a la oferta ${ }^{82}$. A principios del siglo XX todavía no existían casas-cuna en todas las provincias ${ }^{83}$, pero en la de Pontevedra había dos. La de la capital funcionaba desde 1905, se llamada Asilo-Escuela Maternal y estaba al cuidado de las Siervas de María. Sus objetivos eran dar albergue, alimento y educación a

77 En 1900, recibieron ayudas tres madres que no podían amamantar. La primera tenía siete hijos, el más pequeño de un mes; la segunda, era escrofulosa y la tercera, era soltera, pobre y enferma. La duración de las ayudas fue de 2, 4 y 2 años, respectivamente. En 1909 recibió la ayuda una reclusa que no tenía leche, durante el tiempo de su condena. ADP, u.i. 977 y $14.726 / 3$.

78 La ayuda consistió en 90 pesetas mensuales durante los 18 primeros meses de los lactantes y 67,50 pesetas en cada uno de los 6 meses siguientes. Sesiones de la CPP, 9-8-1929 y 20-41931. ADP, u.i. 13.155 , pág. 102 y 13.157, pág. 47, respectivamente.

79 Arenal, C. (1902): sin paginar.

80 Rollet, C. (2001): 149-150.

81 "Labor de la Junta de Valladolid", Pro-Infantia, 49 (1913): 431. García Alcalde, P. (1991): 118.

82 Puig y Alfonso, F. (1927): 127 y 235.

83 En 1908, solo 13 provincias contaban con una. "España. Protección a la infancia”, Pro-Infantia, 6 (1909): 275. 
niños durante el horario laboral de sus madres o padres ${ }^{84}$. Esta institución, que fue fundada por la Junta de Señoras, damas de las familias más destacadas social y económicamente, atendía alrededor de cien criaturas y se financiaba mediante veladas teatrales, donativos, legados y subvenciones municipales y provinciales ${ }^{85}$. Sin embargo, tanto el Ayuntamiento de Pontevedra como la Diputación Provincial no se implicaron en su organización y dirección, y se limitaron a concederle una subvención anual, como hacían con otras instituciones benéficas ${ }^{86}$. La última noticia del Asilo-Escuela Maternal en la prensa apareció en 1922 y, aunque no podamos concretar en que fecha cesó en su actividad, sabemos que en 1925 ya no funcionaba ${ }^{87}$.

La casa-cuna de Vigo, llamada Asilo del Niño Jesús de Praga, fue fundada en 1903 por particulares y acogía a menores entre 2 y 7 años de edad. Estaba atendida por las Hermanas de la Caridad de San Vicente de Paúl, la administraba una Junta de Señoras y se financiaba con lo recaudado en rifas y actos sociales, y con aportaciones de particulares y del Ayuntamiento de Vigo ${ }^{88}$.

\section{Las recuperaciones de los acogidos en la Inclusa de Pontevedra, 1872-1931}

El Reglamento del 14-5-1852 para la ejecución de la Ley de beneficencia de 20-61849 contemplaba respecto a las casas de expósitos la recuperación de los niños dependientes de ellas por parte de sus madres y padres, siempre que éstos observaran buena conducta y abonaran una parte o la totalidad de los gastos que la crianza de su hijo había causado, aunque si no podían realizar este pago el menor les sería devuelto igualmente ${ }^{89}$. Los reglamentos de las inclusas, por tanto, también esta-

84 En una casa-cuna los niños permanecían allí durante el día pero dormían en sus propias casas y no perdían el contacto con sus madres y padres. Sus características, por tanto, eran muy diferentes a las de una inclusa.

85 "Miscelánea provincial", "La velada en el teatro", "Un filántropo”, La Correspondencia gallega, 4.597, 4.961 y 5.757, respectivamente (3-6-1905, 22-8-1906 y 27-4-1909, respectivamente). "Municipio", "En la Escuela Maternal", "Presupuesto de la Diputación Provincial de Pontevedra” y "Al público", El Progreso, 1.244, 1.515, 2.040 y 2.304, respectivamente (7-11914, 28-12-1914, 24-5-1916 y 7-8-1917, respectivamente), disponibles en <http://biblioteca.galiciana.gal>. "España. Protección a la infancia”, Pro-Infantia, 6 (1909): 277.

86 La Diputación Provincial en 1920 concedió subvenciones a 14 instituciones benéficas, entre ellas la Casa de Caridad de Vigo, el Hospital y la Inclusa de Tui, y el Asilo-Escuela Maternal de Pontevedra. "Como se administra nuestra Diputación”, La Raza: semanario, 111(10-3-1920).

87 Junta Provincial de Beneficencia de Pontevedra (1925): 27.

88 "El dr. Ortiz Cano en Vigo", "La rifa de abanicos", "Crónica municipal”, Galicia: diario de Vigo, 76, 91 y 551, respectivamente (20-10-1922, 7-11-1922, 4-7-1924, respectivamente): 1, 3 y 1 , respectivamente, disponibles en 〈http://biblioteca.galiciana.gal〉. Junta Provincial DE Beneficencia de Pontevedra (1926): 64-65.

89 Maza Zorrilla, E. (1987): 235. 
blecían la entrega de los acogidos mediante su naturalización o legitimación, eximiendo del pago de su manutención si se presentaba una declaración de pobreza ${ }^{90}$. Este era el cauce formal, pero también existían entregas informales que requerían muy poca documentación.

Las reclamaciones de niños ingresados en las inclusas que eran resueltas más rápidamente eran las de los hijos legítimos o naturales, es decir, las de los identificados y anotados en el Registro Civil, en el que también constaban los datos de la madre o de ambos padres. Las recuperaciones solían realizarlas las progenitoras, aunque en algunos pocos casos era el padre, un abuelo o bien otro familiar el que la solicitaba. No obstante, no siempre la reclamación de una criatura podía hacerse realidad porque, dada la alta mortalidad en las inclusas, en algunas ocasiones el menor solicitado había fallecido. En la Inclusa de Pontevedra, desde que se creó y, al mismo tiempo, se abrió el torno, en 1872, hasta que se cerró este artilugio en el año 1925, ingresaron 1.926 niños, de los que murieron 946, es decir, un $48,12 \%$, teniendo 745 de ellos menos de un año de edad. Solo lograron sobrevivir 980 criaturas $^{91}$.

\subsection{Las naturalizaciones y las legitimaciones de expósitos}

La naturalización de un expósito comportaba su reconocimiento por uno o dos de los progenitores y el cambio de los apellidos que le había asignado el Registro Civil por los de su madre o los de ambos padres. El reconocimiento de un hijo natural podía hacerse en el acta de nacimiento, en testamento o en otro documento público $^{92}$.

En la Inclusa de Pontevedra hemos encontrado muy pocas naturalizaciones de niños, solo 8, en el período que analizamos, $1872-1931^{93}$. Creemos que, en parte, se debe a que la alta mortalidad de la institución provocaba que, en algunos casos, la naturalización de un expósito determinado no fuera posible. Además, había madres que preferían recuperar a su hijo de manera informal reclamándolo no como tales, sino presentándose ellas como nodrizas sin retribución, como veremos en el apartado 2.4. Siete de los naturalizados habían ingresado en los primeros años de existencia de la Inclusa, y el octavo, en 1918. Todas las naturalizaciones fueron

90 Reglamento de la Casa de Maternidad... (1883): 53-54. Reglamento. Casa Provincial de Maternidad... (1894): 24-25.

91 Analizados los ingresados en los años 1873, 1876, 1879, 1882, 1885, 1888, 1891, 1894, 1897 , 1900, 1903, 1906, 1909, 1912, 1915, 1918, 1921 y 1924. ADP, u.i. 14.721/2 al 14.730/2.

92 Código civil español (1889): 157-158, art. 129-136.

93 Años revisados: 1872, 1873, 1878, 1883, 1888, 1893, 1898, 1903, 1906, 1909, 1912, 1915 , 1918, 1921, 1924. ADP, u.i. 14.721/2-14.731/1. 
efectuadas por mujeres, y solo a una de ellas, en 1879, se le cobraron los gastos ocasionados por la permanencia del niño durante cuatro meses en el establecimiento benéfico, a pesar de que esta madre era soltera, menor de edad, y lo había dejado en el torno mientras trabajaba de nodriza interna en el propio establecimiento. Sin embargo, dos progenitoras fueron eximidas del pago al presentar un certificado conforme no eran contribuyentes ${ }^{94}$.

Las madres de los incluseros naturalizados reflejaban la situación de una parte importante de las mujeres gallegas. Su pobreza la vemos en que una era sirvienta y otra pobre de solemnidad, todas habían dejado a sus hijos en el torno con prendas de ropas viejas, y su nivel de instrucción apenas les alcanzaba para firmar la solicitud de reclamación de su niño. Además, algunas de ellas no podían contar con el salario de un marido, pues dos eran solteras y una viuda ${ }^{95}$.

La legitimación de un expósito se producía cuando unos progenitores declaraban serlo de ese menor, justificaban estar casados y solicitaban la rectificación de la inscripción de su hijo en el Registro Civil para que constaran ellos como padres legítimos ${ }^{96}$. En la Inclusa de Pontevedra, en los años revisados entre 1872 y $1924^{97}$, no hemos encontrado legitimación alguna apuntada en los libros de registro de los expósitos.

\subsection{Las recuperaciones de los niños con padres conocidos}

Había criaturas que habían sido anotadas en el Registro Civil por su madre o ambos progenitores, y que habían entrado en la Inclusa de Pontevedra por causas de fuerza mayor y por orden de la Comisión Provincial, del gobernador civil o de un juez. Si estos menores eran reclamados por sus madres o sus padres, la Inclusa se los entregaba sin que tuvieran que presentar documentación alguna, puesto que el parentesco ya se había justificado cuando se había producido el ingreso. Para analizar estas recuperaciones hemos establecido dos etapas, divididas por la Ley de Protección a la Infancia del 12-8-1904, entre cuyos objetivos estaban los de velar por los niños dependientes de las inclusas y evitar la mendicidad infantil ${ }^{98}$.

94 Rodríguez Martín, A. M. (2008): 370-371.

95 ADP, u.i. 984 y 14.721/2-14.731/1. Sesión de la CPP, 18-2-1927. ADP, u.i. 13.152, pág. 10. Rodríguez Martín, A. M. (2008): 370.

96 Código civil español (1889): 154-155, art. 119-121.

97 Años revisados: 1872, 1873, 1878, 1883, 1888, 1893, 1898, 1903, 1906, 1909, 1912, 1915 , 1918, 1921, 1924. ADP. u.i. 14.721/2-14.731/1.

98 Consejo Superior de Protección a la Infancia (1908): 15. 
En la Inclusa de Pontevedra, antes de la ley de 1904 ya citada, entraron pocos hijos legítimos o naturales, solo $24^{99}$. Se trataba de criaturas cuyos progenitores eran pobres y estaban enfermos o habían fallecido, o bien cuyas madres estaban dementes, eran discapacitadas intelectuales o no podían amamantar porque no tenían leche y, además, no podían pagar a una nodriza. También ingresaban menores abandonados por haberse ausentado su progenitora o por estar en la cárcel cumpliendo condena ${ }^{100}$. Otras inclusas también acogían a este tipo de niños cuya característica fundamental era la de ser hijos de madres y padres pobres ${ }^{101}$.

En la Inclusa de Pontevedra las recuperaciones de estas criaturas fueron pocas porque su mortalidad, al igual que la del resto de ingresados, era elevada. Además, algunos ingresaban ya huérfanos totales y otros tenían madres cuya discapacidad o enfermedad las incapacitaba para cuidarlos, o progenitores cuya pobreza, unida a una serie de circunstancias negativas, no les permitía hacerse cargo de sus niños.

Después de la Ley de Protección a la Infancia de 1904 aumentó el número de ingresos en la Inclusa de hijos legítimos y naturales, aunque seguían representando un porcentaje muy bajo del total de acogidos. Los motivos por los que entraban estos niños eran los que acabamos de ver al analizar los años anteriores, y la duración de su estancia en la Institución dependía del fin de su lactancia, de la salida de la madre del hospital o de la cárcel, o de si existía algún familiar que pudiera encargarse de ellos ${ }^{102}$. En algunos casos, estos menores se quedaban de forma definitiva bajo la tutela de la Inclusa y a los 7 años, como estaba establecido reglamentariamente para todos los acogidos, ingresaban en el Hospicio ${ }^{103}$ o bien la nodriza que los había cuidado se quedaba con ellos de forma gratuita. No obstante, casi la mitad de estos hijos legítimos o naturales supervivientes fueron recogidos por sus madres o padres, o bien por otros familiares (véase tabla $\mathrm{n}^{\circ} 1$ ).

99 Consideramos a los ingresados en los años 1873, 1878, 1883, 1888, 1893, 1898 y 1903. ADP, u.i. $14.721 / 2-14.725 / 1$

100 Sesiones de la CPP, 5-2-1890, 4-4-1892, 17-6-1893, 7-9-1893, 10-9-1893, 15-11-1893, 13-21895, 12-11-1895, 9-10-1897 y 1-12-1897. ADP, u.i. 13.033, pág. 46; 13.035, pág. 84; 13.036, págs. 126 y 195; 13.036, págs. 238-239; 13.038, págs. 58-59 y 232; 13.040, págs. 158 y 180 181 , respectivamente.

101 Sanglard, G. (2016): 344-348 y 350-351.

102 El caso más llamativo es el de cuatro hermanos que ingresaron, en 1904, en la Inclusa y el Hospicio, según su edad, porque su progenitora, demente, los había dejado sin comida y había desaparecido durante unos días. El padre, que estaba en América, cuando se enteró, logró llevarlos a todos consigo. ADP, u.i. 984 y 14.725/2.

103 Algunos menores reclamados lo fueron estando ya en el Hospicio, como dos muchachas de 17 y 18 años, respectivamente, que habían ingresado en la Inclusa en 1906. ADP, u.i. $14.725 / 3$ y $14.726 / 1$. 


\begin{tabular}{|c|c|c|c|c|c|c|c|}
\hline \multicolumn{6}{|c|}{ Tabla $n^{\circ} 1$. Destino de los hijos legítimos y naturales ingresados en la Inclusa de Pontevedra, } \\
$1906-1924104$
\end{tabular}

Fuentes: elaboración propia a partir de los libros de ingresos de la Inclusa y del Hospicio de Pontevedra, 1906-1924, ADP, u.i. 14.725/3-14.730/2, 14.740/2 y 14.741/1-2; de los expedientes personales de los ingresados, ADP, u.i. 943, 944, 962 y 977; y del libro de sesiones de la CPP, ADP, u.i. 13.151, pág. 59.

A partir de 1925, año en el que se cerró el torno, a las circunstancias que justificaban el ingreso de hijos legítimos o naturales en la Inclusa había que añadirle la de la imposibilidad de algunas madres solteras o viudas de compaginar su trabajo de sirvienta, que consideraban indispensable para su subsistencia, con la lactancia y cuidado de su niño. Pasado un tiempo, estas mujeres solían recoger a sus hijos, por lo que el porcentaje de recuperaciones aumentó (véase tabla no 2). Las solicitudes de devolución de las criaturas fueron realizadas, mayoritariamente, por las progenitoras, sobre todo solteras, que alegaban que tenían una situación económica más saneada o que habían desaparecido los motivos que les habían obligado a ingresar a sus niños. En algunos casos la mejora era tan débil que solo alcanzaba para sacar de la Inclusa a uno de los dos hijos mientras que el otro permanecía allí unos años más. En otras ocasiones, la convivencia del menor con el familiar que lo había reclamado no duraba mucho ${ }^{105}$, como en el caso de una madre soltera que tuvo que reingresar a su criatura porque no podía mantenerla, “...por tener que dedicarse al servicio doméstico y encontrarse enferma"106.

En resumen, del total de los niños con padres conocidos reclamados en 19061930, que fueron 34, la mayor parte lo fue por mujeres en solitario: 20 por sus madres solteras y 3 por sus abuelas ${ }^{107}$. La Inclusa facilitó siempre la entrega de estos acogidos, aunque teniendo en cuenta que las mujeres casadas que habían ingresado a su hijo estando solteras necesitaban la autorización de su esposo ${ }^{108}$. A pesar

104 Hemos analizado los ingresados en los años 1906, 1909, 1912, 1915, 1918, 1921 y 1924.

105 Como la de un asilado entregado en 1931 a su abuela viuda y que tuvo de ingresar solo dos años después en el Hospicio. ADP, u.i. 14.730/3.

106 Sesión de la CG, 15-7-1932. ADP, u.i. 13.158, pág. 73.

107 Dos de las abuelas recogieron sendos menores que habían sido admitidos en la Inclusa por enfermedad grave u hospitalización de la progenitora, por lo que podemos pensar en su probable fallecimiento. ADP, u.i. 986. Además, sesión de la CG, 28-8-1935. ADP, u.i. 13.161, pág. 111.

108 Sesión de la CG, 24-6-1932. ADP, u.i. 13.158, pág. 64. 
de ello, una progenitora que no la consiguió solicitó que fuera la abuela materna la que se hiciera cargo de la criatura. La Inclusa lo aceptó, aunque con la condición de que tendría que entregarla si algún pariente con más derecho la reclamara ${ }^{109}$.

\begin{tabular}{|c|c|c|c|c|c|c|c|}
\hline \multicolumn{2}{|c|}{ Tabla $n^{\circ}$ 2. Destino de los hijos legítimos y naturales ingresados en la Inclusa de Pontevedra, } \\
1927 y 1930
\end{tabular}

Fuentes: elaboración propia a partir del libro de ingresos de la Inclusa de Pontevedra, 1927-1930, ADP, u.i. 14.730/2; de los expedientes personales de los ingresados, ADP, u.i. 976 y 186; y del libro de sesiones de la CPP, ADP, u.i. 13.156 .

\subsection{Las recuperaciones de bijos de padres desconocidos}

Los niños que entraban por el torno o los que ingresaban tras haber sido expuestos fuera de él, eran anotados en la Inclusa de Pontevedra como expósitos cuyos padres eran desconocidos. Sin embargo, a partir de 1925, cuando se cerró el torno, los menores que entraban lo hacían tras haber formado la Diputación Provincial un expediente con todas las circunstancias que motivaban su entrada, por lo que tanto ellos como sus madres o ambos progenitores estaban identificados.

Resulta muy difícil establecer el porcentaje de recuperaciones de los expósitos de la Inclusa de Pontevedra porque, como veremos en el apartado siguiente, algunos de ellos eran solicitados por mujeres que se ofrecían a lactarlos gratuitamente, como nodrizas sin retribución aunque, en realidad, un número apreciable de ellas fueran sus madres. Por otro lado, eran dejadas criaturas en el torno, sobre todo a partir de principios del siglo XX, con notas en las que se informaba de la parroquia en la que habían sido bautizadas y del nombre de la madre o de ambos progenitores, pero no portaban ni la partida de bautismo ni el certificado de la inscripción en el Registro Civil. Estos niños, en algunas ocasiones, eran dados a lactar a mujeres que tenían uno o los dos apellidos iguales a los que se solicitaban en la nota con la que habían sido abandonados, por lo que podemos pensar que se trataba de las propias madres o familiares. A todo esto hay que agregarle que algunos menores eran echados al torno sin nota o documento alguno habiendo sido previamente

109 Ibidem, pág. 36. 
inscritos por sus progenitora o progenitores como hijos suyos en el Registro Civil. Por esta razón, es muy difícil establecer la verdadera situación legal de bastantes acogidos y la forma en la que eran entregados a los familiares que los reclamaban, dado que la Inclusa de Pontevedra no siguió los cauces legales establecidos para las entregas, que eran la naturalización y la legitimación de los niños en cuestión. Los expedientes personales de los incluseros podrían ofrecernos más información, pero el problema es que de los del siglo XIX faltan muchos y de los existentes algunos solo contienen la partida de bautismo de la criatura tras haber sido ingresada en la Inclusa. Por estas razones, nada más hemos cuantificado las recuperaciones ocurridas a partir de los primeros años del siglo XX y hasta el cierre del torno en 1925. En total se produjeron 33, y de ellas, el 60,61\% en solo dos años, 1921 y 1924. Del total de las reclamaciones, casi la mitad fue realizada por las madres en solitario (véase tabla $n^{\circ} 3$ ). De las seis firmadas por los padres, tres se correspondían a hombres viudos y otra al esposo de una mujer demente.

\begin{tabular}{|c|c|c|c|c|c|c|c|}
\hline \multicolumn{7}{|c|}{ Tabla $\mathrm{n}^{\circ}$ 3. Niños recuperados por sus padres y familiares habiendo sido ingresados en la } \\
Inclusa de Pontevedra como hijos de padres desconocidos 110
\end{tabular}

Fuentes: elaboración propia a partir de los libros de ingresos de la Inclusa y del Hospicio de Pontevedra, 1906-1924, ADP, u.i. 14.725/3-14.730/2, 14.740/1-2 y 14.741/1-2; de los expedientes personales de los expósitos, ADP, u.i. 943, 944, 962, 975 y 977; y de los libros de sesiones de la CPP, ADP, u.i. 13.152-13.155.

En los primeros años de funcionamiento de la Inclusa, los expósitos dejados en el torno eran entregados a sus madres o padres si los reclamaban, "entregado a...por haber justificado ser su verdadera madre"111, pero no hemos encontrado la forma en la que se acreditaba el parentesco. En 1873, una mujer soltera, que había echado al torno a su hijo de 3 años, detalló las prendas que llevaba cuando lo abandonó y se lo entregaron. Y lo mismo ocurrió en otros casos en esa década, en los que bastó la simple confrontación de las notas que llevaban los expósitos al ser depositados en el torno con las copias que presentaban las que decían ser sus progenitoras ${ }^{112}$. Sin embargo, en 1879 , una entrega se hizo mediante un acta

110 Hemos analizado los ingresados en los años 1906, 1909, 1912, 1915, 1918, 1921 y 1924.

111 ADP, u.i. $14.721 / 2$.

112 ADP, u.i. 943, 984, 961, 14.722/1 y 14.724/2-3. 
notarial que comportaba obligaciones, “...la recibe como tal hija suya, obligándose a acreditar la maternidad en la forma que la ley exige y a la vez a satisfacer inmediatamente los gastos ocasionados en el Establecimiento hasta la fecha" ${ }^{\text {"113. }}$ A principios de la tercera década del siglo XX, la Inclusa exigía ya más documentación. La persona que reclamara a un asilado como hijo o familiar suyo debía presentar el certificado de buena conducta librado por su ayuntamiento y el del parto expedido por el Hospital o bien un documento que acreditara el parentesco ${ }^{114}$. A partir de 1926, era imprescindible, además, el certificado no padecer enfermedad infecto-contagiosa alguna ${ }^{115}$ y la justificación de la maternidad, "cuyo extremo habrá de acreditar mediante el oportuno reconocimiento"116. Además, para no pagar por el cuidado y alimentación del menor que se reclamaba, era necesario acreditar que no se figuraba en los repartimientos de la contribución territorial y en la matrícula industrial del municipio ${ }^{117}$.

También eran entregados, después de una serie de trámites, los niños que habían sido expuestos a la puerta de una casa, en una calle o en otro lugar público. Lo mismo ocurría con los hijos legítimos dejados en el torno que habían sido inscritos por la Inclusa en el Registro Civil como hijos de padres desconocidos al no conocer su filiación. A algunos de estos menores se les impusieron los apellidos que constaban en la nota que portaban entre sus ropas y que luego resultó que eran iguales a los de sus progenitores, como se puede ver en las pocas instancias de recuperación que se realizaron ${ }^{118}$. En todos los casos la Inclusa atendió positivamente las solicitudes, aunque de diversas maneras. En 1910, unos consortes reclamaron a la hija a la que habían depositado doce años antes en el torno, y para ello presentaron una nota igual a la que llevaba la niña entre sus ropas al ser abandonada. La Inclusa les entregó la asilada pero sin reconocerles su condición de padres, considerándoles solo protectores y encargados de dicha menor, y advirtiéndoles de que sería recogida si se presentaba alguien con mejor derecho o si estuviera maltratada ${ }^{119}$. Sin embargo, posteriormente, en la década de los 20, este tipo de niños se entregaban a sus progenitores como tales, tras la presentación del certificado de buena conducta y de un documento que acreditase el parentesco ${ }^{120}$. Ninguno de estos hijos legítimos fue recogido siendo

113 Acta notarial de la entrega de la expósita 337/1879, 30-4-1879. ADP, u.i. 943.

114 ADP, u.i. 944 y 975.

115 Sesiones de la CPP, 28-1-1927 y 19-4-1929. ADP, u.i. 13.152, pág. 6 y 13.155, págs. 54-55, respectivamente.

116 Sesión de la CPP, 16-11-1928. ADP, u.i. 13.154, pág. 89.

117 ADP, u.i. 944 y $14.729 / 3$.

118 ADP, u.i. 977 y $14.726 / 1$.

119 ADP, u.i. 977.

120 ADP, u.i. 975 y 14.730/2. 
lactante, creemos que porque su abandono habría sido provocado por la pobreza u otras circunstancias que impedían que fueran amamantados, como unos trillizos huérfanos de madre ${ }^{121}$.

En bastantes instancias se explicaban las razones por las que se quería recuperar al menor que se había echado al torno, "...quiere cuidar a su referida hija, pues le atormenta diariamente el disgusto de verse separada de esta"122 o "...siente renacer su amor de madre"123. En un caso, una mujer afirmaba que su situación había cambiado porque se había casado con el padre de su niña, “...y habiéndose enterado que su dicha hija suya vive, y deseando hoy tenerla a su lado para mantenerla y educarla por contar con medios para ello por haberse casado...”124.

En bastantes instancias en las que se reclamaban acogidos echados anteriormente al torno había una justificación, “...no teniendo recursos entonces para sostenerla y cuidarla..." ${ }^{25}$, “...por no poder en aquella época atender a su cuidado"126. También se explicaban las razones de los abandonos en las notas. Se trataba de la pobreza, la enfermedad, el fallecimiento o la demencia de uno o los dos progenitores, "Se echa por falta de recursos y se pasará a recogerla"127, “...es depositada en el torno por haber quedado uerfana la quedan 4 hermanos y parientes en Portugal"128, "va a esa inclusa por la muerte de su madre"129, “... por estar su madre enferma y se recojera cuando su salud se lo permita” ${ }^{130}$. Estas madres o padres que habían echado al torno a sus hijos o los habían expuesto en cualquier otro lugar para que fueran enviados a la Inclusa, habían elegido la vía rápida de entrada en el establecimiento benéfico, que comportaba la lactancia inmediata. La vía lenta, sin embargo, era difícil de seguir en una sociedad con mucho analfabetismo, sobre todo femenino. Consistía en la solicitud de admisión mediante instancia, la formación de un expediente y el cumplimiento de unos determinados requisitos: presentación de la partida de bautismo y certificado de orfandad del menor, justificación de la absoluta pobreza o enfermedad de los padres, y ausencia o pobreza de los parientes obligados a proporcionar alimentos al niño, según establecía el Código Civil ${ }^{131}$. Por otro lado, ya vimos que la Inclusa concedió pocas ayudas a la lactancia y que las Gotas de Leche solo empezaron a




funcionar a principios del siglo XX y nada más que en las ciudades. El depósito en el torno, entonces, significaría para algunas madres y padres darle más probabilidades de sobrevivir a su hijo.

Algunas de las notas que llevaban estos menores al ser abandonados expresaban la intención de sus progenitores de recuperarlos pasado un tiempo, pero pocas ponían un plazo concreto ${ }^{132}$. Del total de los 33 niños recogidos, llevaran o no nota, el 55,54\% lo fue cuando ya había pasado el período de lactancia e, incluso, algunos cuando tenían siete o más años y estaban ya en el Hospicio ${ }^{133}$. En algún caso, la tardanza de algunas madres en solicitar a la Inclusa la devolución de su hijo podía deberse a que su profesión de sirvienta dificultaba su cuidado ${ }^{134}$. En otras ocasiones, la causa podía ser no contar con el salario de un marido, por tratarse de mujeres solteras. En esta situación estaban cinco de las madres que reclamaron a sus niños. También la emigración a América pudo haber influido en esa tardanza. Una progenitora soltera y unos consortes solicitaron la entrega de sus respectivas hijas desde Argentina ${ }^{135}$. Estos últimos achacaron a cuestiones económicas el haber tardado 11 años en reclamar a la niña que habían depositado en el torno, “...y por no tener posibles para poderla sacar (a la menor) debido alas consecuencias Europeas pues en todos los países a repercutado la nesicidad"136.

Aunque acabamos de ver que para la recuperación de un expósito la Inclusa exigía una serie de documentos, en general facilitaba la reunificación familiar ${ }^{137}$, incluso si los reclamantes vivían en Argentina y solicitaban que el menor fuera llevado allí por una persona respetable o un familiar ${ }^{138}$. Solo encontré dos casos en los que la Institución no hizo entrega de dos acogidos reclamados. El primero, en 1906, comenzó cuando una nodriza, a través de su párroco, solicitó que no le retirasen la niña que cuidaba y que había sido reclamada por su madre presentando una nota igual a la que había dejado en el torno con la recién nacida. El gobernador civil pidió información sobre el asunto y el administrador de la Inclusa declaró que

132 Solo en una nota se especificaba el plazo, "será rrecogido a laedad de 3 años", pero el niño fue reclamado cuando tenía 17 años. ADP, u.i. 14.730/2 y 14.741/2.

133 ADP, u.i. 941, 943, 962, 14.725/3-14.730/2, 14.740/1-2 y 14.741/1-2. Sesión de la CPP, 7-121928. ADP, u.i. 13.154, pág. 95.

134 ADP, u.i. 943.

135 ADP, u.i. 944, 962, 14.727/2 y 14.729/3.

136 Escrito del padre de la asilada 3.701/1912 a la Inclusa, 14-4-1923. ADP, u.i. 962 y 14.727/2.

137 A los 11 años de edad, la expósita 4.358/1915 fue trasladada a la Casa de la Caridad de Vigo porque allí residía su madre. Sesión de la CPP, 16-7-1926. ADP, u.i. 13.151, pág. 59.

138 Las acogidas 3.701/12 y 5.168/21 fueron entregadas a una tía y a un matrimonio de buena conducta comprobada, respectivamente, que las llevarían a Argentina para estar al lado de su madre y de sus padres, respectivamente. ADP, u.i. 14.727/2, 944 y 962. 
se entregaban criaturas a sus progenitoras sin indagar sobre su conducta y aceptando la maternidad que declaraban, ...esta Administración ignora la conducta de xxx (la madre) ni tiene medios de hacer averiguaciones en este sentido...cumpliendo con su deber y a fin de evitar responsabilidades, estaba en el curso de hacer dicha entrega (de la niña), toda vez que a este establecimiento le está prohibido, dado su carácter reservado hacer investigaciones sobre la maternidad de los expósitos ${ }^{139}$.

El gobernador, entonces, decidió que la niña quedara con su nodriza ${ }^{140}$ y que no se entregara a la madre debido la mala conducta privada de ésta y a que no había justificado su maternidad de manera firme,

...aun prescindiendo de la mayor o menor certeza respecto a la alegación que hace la reclamante de ser madre de la mencionada niña, la conducta privada de xxx, impide le sea entregada dicha expósita, por lo cual he acordado sea retenida, ya en ese establecimiento benéfico, o ya en poder de la nodriza que la tiene a su cuidado ${ }^{141}$.

El segundo caso es el de una mujer soltera a la que, en 1927, se le entregó su hija dejada en el torno tres años antes. Aunque había justificado su maternidad y buena conducta, la Inclusa decidió retirarle la criatura por cuestiones de moralidad, "Esta Casa habiéndose enterado con posterioridad y por informes particulares fidedignos de que la reclamante se dedica públicamente a una vida licenciosa de cuyo ambiente parecía humano retirar a la menor...”142. Al año siguiente, sin embargo, se entregó a los abuelos, “...el cuidado de la expósita correrá a cargo de aquéllos,

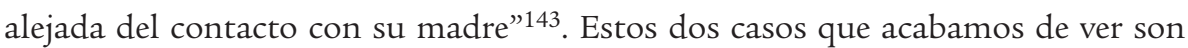
excepcionales porque la Inclusa no indagaba de forma reservada sobre la conducta moral de las personas que en calidad de madres o padres, cualquiera que fuera su estado civil, reclamaban un hijo. Esta postura creemos que evidenciaba el deseo de la Institución de favorecer que sus acogidos estuvieran al lado de sus progenitores, aunque también podría existir una motivación económica: estos niños recuperados por su familia significaban un ahorro para la Inclusa y, por consiguiente, para la Diputación Provincial. Este deseo de reducir gastos lo podemos ver también en la decisión de cerrar el torno en 1925. En principio, la Diputación explicó que se debía a cuestiones sanitarias y lo que se buscaba era evitar defunciones y conta-

139 Informe del administrador de la Inclusa al gobernador civil, 8-10-1906. ADP, u.i. 984.

140 ADP, u.i. 14.725/1.

141 Oficio del gobernador civil a la CPP, 16-10-1906. ADP, u.i. 984.

142 Sesión de la CPP, 15-7-1927. ADP, u.i. 13.153, pág. 4.

143 Sesión de la CPP, 11-5-1928. ADP, 13.154, pág. 38. Además, ADP, u.i. 14.730/2. 
gios ${ }^{144}$ pero, al año siguiente, el administrador de la Inclusa presentó un informe sobre los beneficios del cierre en el que se remarcaba el ahorro conseguido al descender el número de ingresados y, por consiguiente, el gasto en sueldos de las nodrizas. Ante el contenido del informe, la Comisión Permanente Provincial expresó formalmente su satisfacción, y el torno no volvió a abrirse más ${ }^{145}$.

\subsection{Los acogidos entregados a nodrizas sin retribución}

Las nodrizas sin retribución eran mujeres que recogían a incluseros, ya fueran lactantes o destetados menores de 7 años, para alimentarlos, cuidarlos y quedárselos sin cobrar salario alguno. En la Inclusa de Pontevedra estas amas no estaban anotadas en el libro oficial de registro de las nodrizas, pero hemos podido calcular su número y conocer sus características porque ya desde 1873 constaban claramente en los libros de ingresos de expósitos, en donde se anotaban esta clase de entregas. Sin embargo, a partir del cierre del torno en 1925, cuando los niños ya ingresaron identificados y se establecieron una serie de normas para las personas que quisieran recoger incluseros, este tipo de amas desapareció. En total, entre 1873 y 1924, de los 1.660 ingresados fueron recogidos por nodrizas sin sueldo 159, es decir, el $9,58 \%{ }^{146}$. Muchos de estos menores habían sido echados en el torno con notas en las que se solicitaba que se inscribieran en el Registro Civil con uno o dos apellidos concretos que, en muchas ocasiones, coincidían con los de las amas sin salario que luego los recogían. Después de examinar el período 1906-1924 hemos visto que hay esa coincidencia en el 51,68\% de los casos e, incluso, en el último año citado, en el $100 \%{ }^{147}$. Esta circunstancia nos lleva a creer que, de estas nodrizas sin sueldo, bastantes eran las madres solteras de estos expósitos, como J.S.B., sirvienta, residente en Madrid, a la que se le entregó la asilada de 3 años J.S.B. ${ }^{148}$ Además, en algunas ocasiones, se afirmaba el parentesco en la instancia de solicitud de entrega del inclusero o en el certificado de buena conducta del ama expedido por la alcaldía correspondiente ${ }^{149}$. Veamos un caso: una niña había sido echada en el torno envuelta en paños viejos y llevando una nota en la que constaba el nombre de la

144 "El cierre de la Inclusa”, El Diario de Pontevedra, 12.121 (8-5-1925), disponible en < $\underline{\text { http:// }}$ biblioteca.galiciana.gal>.

145 Sesión de la CPP, 29-10-1926. ADP, u.i. 13.151, págs. 84-85.

146 Tenemos en cuenta a los ingresados en los años 1873, 1878, 1883, 1888, 1893, 1898, 1903, 1906, 1909, 1912, 1915, 1918, 1921 y 1924. ADP, u.i. 14.721/2 al 14.730/2. RodríGuEz MARTín, A.M. (2007): 245-247.

147 Consideramos a los ingresados en los años 1906, 1909, 1912, 1915, 1918, 1921 y 1924. ADP, u.i. $14.725 / 3-14.730 / 2$.

148 ADP, u.i. $14.729 / 3$.

149 ADP, u.i. 944 y $14.729 / 3$. 
madre y la razón por la que se producía el abandono, que era la falta de recursos. Después de cinco días, esta asilada fue solicitada por una mujer que tenía su mismo apellido y que se ofrecía como nodriza sin salario, y en la carta de su alcalde no se ocultaba la relación entre ambas, “...tan pronto pudo (la solicitante) abandonar el lecho para rogar que me dirija a $V$. pidiéndole haga entrega de su hija, pues quiere vivir con ella en compañía de sus padres"150. En otros casos, la coincidencia intencionada entre el apellido del ama sin sueldo y el del expósito del que se hacía cargo ya indicaba la probable existencia de una relación familiar que sería la causa de que algunas mujeres de pueblos de Lugo y Orense se prestasen a cuidar de forma permanente a un inclusero de pocos días de vida, de una provincia distinta a la suya y sin recibir nada a cambio ${ }^{151}$. También los lazos familiares explicarían que dos mujeres casadas, vecinas de Lugo y de una aldea de A Coruña, respectivamente, se hicieran cargo de sendos niños, ya destetados, que llevaban el apellido de ellas y no los de sus maridos ${ }^{152}$.

Muchos de los menores entregados en 1906-1924 a nodrizas sin sueldo habían sido depositados en el torno con una nota o trozo de papel, concretamente el $75,82 \%$, pero si solo consideramos a los que fueron solicitados por amas con sus mismos apellidos, el porcentaje sube al $80,43 \% 153$. Analizando las notas de este último grupo de expósitos podemos ver que en ellas solía haber una explicación de las causas del abandono. El deshonor o la soltería de la progenitora no eran citadas, pero sí, y en muchas ocasiones, su pobreza y su enfermedad, “...por enfermedad de la madre se deposita en este benefico establecimiento"154. "...este niño ba por falta de recursos de su madre"155. Frecuentemente las notas también incluían la promesa de recogida de la criatura, unida, en bastantes ocasiones, a la explicación del abandono, "Esta niña se hecha por necesidad...Se recojerá lo más pronto posible"156, "...esta niña se echa por falta de recursos para criarla y tan pronto pueda la ede quitar”157. La pobreza se veía reflejada en la manera en como iban vestidas las criaturas al ser echadas en el torno. Sus ropas están descritas en los libros de registro de ingresos de la Inclusa como trapos viejos o muy viejos. Otro elemento que se repetía en las notas era la solicitud de buenos cuidados,

150 Oficio del alcalde de Vigo al director de la Inclusa, 23-6-1921. ADP, u.i. 944.

151 ADP, u.i. $14.726 / 3,14.727 / 2$ y $14.729 / 1$.

152 ADP, u.i. $14.725 / 3$ y $14.726 / 3$.

153 Estudiamos a los ingresados en los años 1906, 1909, 1912, 1915, 1918, 1921 y 1924. ADP, u.i. $14.725 / 3-14.730 / 2$.

154 ADP, u.i. $14.730 / 2$.

155 ADP, u.i. $14.728 / 2$.

156 ADP, u.i. $14.726 / 3$.

157 ADP, u.i. 14.725/3. 
"rruego cuiden bien a esta niña"158, basándose en que el abandono se había producido por necesidad, "Les ruega la cuiden bien pues es por falta de recursos"159, y en que era temporal, “...y Dios mediante pronto se sacara y se le ruega a la Revda. Madre Superiora sea bien recogida" ${ }^{\text {160 }}$. Por estas razones, también se pedía que el expósito no fuera enviado fuera de la provincia de Pontevedra, "tengo mucho interés en retirarle pronto por lo tanto Ruego muy favorecidamente no le den a fuera"161 "...se desea que pase a buenas manos que se gratificara y que no salga de esta Provincia"162. En algunas de estas notas, además, constaba la fecha de nacimiento del menor o la de su depósito en el torno, y el ruego de que se conservase el papel, “...se desea se conserve este apunte"163. El motivo es que como muchas veces las notas se hacían por duplicado, la copia que guardaba la madre serviría posteriormente como elemento de identificación si luego reclamaba al niño, dado que se confrontaría con la que la Inclusa había guardado. Vemos, pues, que las notas mismas y su contenido eran un elemento que individualizaba al inclusero. Y por si todo esto no era suficiente, muchas veces se les ponían a los niños cadenitas con medallas, escapularios e, incluso, un rosario. Todos estos elementos vistos hasta ahora parecen indicar que muchos de los expósitos cuyos apellidos coincidían con los de sus nodrizas sin retribución, más que haber sido abandonados, solo habían sido depositados temporalmente en la Inclusa con notas y objetos que facilitarían su posterior recuperación. El motivo por el que creemos que actuaban así algunas madres sería, en algunos casos, no poder amamantar a su hijo ni tener dinero para pagar una nodriza. A otras, como las sirvientas ${ }^{164}$, les sería imposible conciliar su trabajo con el cuidado de un lactante, y a algunas el echar a su niño al torno les permitiría emplearse como amas de lactancia particular o continuar trabajando $y$, después de un determinado período de tiempo, muchas veces hasta el destete del hijo e, incluso, hasta más tarde, presentarse como nodriza sin retribución y recogerlo sin que la Inclusa pusiera dificultades. Esta manera de actuar era cada vez más frecuente, y si de la generación de 1906 fueron recogidos por estas amas sin sueldo 3 expósitos, de la de 1924 lo fueron $10^{165}$. Del total de los 46 incluseros entregados a estas nodrizas, casi la mitad tenía más de 15 meses, es decir, estaban

\footnotetext{
158 ADP, u.i. $14.729 / 1$.

159 ADP, u.i. $14.730 / 2$.

160 ADP, u.i. $14.728 / 2$.

161 ADP, u.i. $14.730 / 2$.

162 ADP, u.i. $14.725 / 3$.

163 ADP, u.i. $14.726 / 3$.

164 Sirvientas solteras y, a la vez, nodrizas sin retribución de los expósitos 5.128/1921 y 5.563/1924. ADP, u.i. $14.728 / 3$ y $14.720 / 2$.

165 Tenemos en cuenta a los ingresados en los años 1906, 1909, 1912, 1915, 1918, 1921 y 1924. ADP, u.i. 14.725/3-14.731/1.
} 
ya destetados e, incluso, muchos de ellos habían cumplido ya los 3 años (véase tabla $\left.n^{\circ} 4\right)$.

\begin{tabular}{|c|c|c|c|c|c|c|c|}
\hline \multirow[b]{2}{*}{ Años } & \multicolumn{2}{|c|}{$0-15$ meses } & \multicolumn{2}{|c|}{15 meses - 3 ańos } & \multicolumn{2}{|c|}{ más de 3 años } & \multirow{2}{*}{ Total } \\
\hline & Número & $\%$ & Número & $\%$ & Número & $\%$ & \\
\hline 1906-1924 & 24 & 52,17 & 11 & 23,91 & 11 & 23,91 & 46 \\
\hline
\end{tabular}

Fuentes: elaboración propia a partir de los libros de ingresos de la Inclusa de Pontevedra, 1906-1924, ADP, u.i. 14.725/3-14.730/2.

La edad a la que fueron depositados en el torno estos expósitos era de uno o pocos días de vida, aunque algunos, el 26,09\%, contaban con más de un mes, e incluso, con uno o dos años de edad. Estos niños ya mayores también llevaban notas entre sus ropas que contenían la explicación de la causa por la que sus madres o padres, después de haberlos tenido consigo durante un cierto período de tiempo, los dejaban en la Inclusa. Se trataba, en todos los casos, de la pobreza y la imposibilidad de encargarse de su cuidado: "por no tener sus padres recursos para criarlo..."167, "no podemos criarla"168.

La forma de actuar de las amas sin salario cuyo apellido coincidía con el del menor que sacaban de la Inclusa implicaba el ahorro de los trámites que conllevaban una naturalización o una legitimación, dado que estas mujeres solo necesitaban un informe parroquial de su conducta y, si el niño que se recogía era un lactante, acreditación médica de tener leche. Esta recuperación de su hijo tan sencilla era muy conveniente porque, como ya vimos en el apartado 1.1, había mucho analfabetismo femenino. Estas nodrizas sin retribución, en gran proporción solteras ${ }^{169}$, utilizaban la Inclusa para no separarse definitivamente de su niño porque las mujeres pobres trabajaban y el tener que ocuparse también de un lactante era tarea difícil. Además, las ayudas que las madres podían tener eran escasas porque las casas-cunas eran pocas y con capacidad limitada, y si el problema era la falta de leche o una enfermedad que impedía la lactancia, las Gotas de Leche tenían el inconveniente de que solo existían en las ciudades y, además, nacieron ya avanzado el siglo XX.

166 Idem

167 ADP, u.i. $14.726 / 3$.

168 ADP, u.i. $14.728 / 2$

169 De las 46 nodrizas sin retribución que recogieron expósitos con sus mismos apellidos conocemos el estado civil de 26 de ellas, y era el de soltera. 
Más de la mitad de las amas sin retribución con apellidos iguales a los expósitos que recogían vivían en la ciudad de Pontevedra y, sobre todo, en Vigo (véase tabla $\left.n^{\circ} 5\right)$,

Tabla $n^{\circ} 5$. Residencia de las nodrizas sin retribución con los mismos apellidos que los expósitos de la Inclusa de Pontevedra que recogían, 1906-1924 170

\begin{tabular}{|c|c|c|c|c|c|c|}
\hline \multirow[b]{2}{*}{ Años } & \multicolumn{2}{|c|}{ Municipios } & \multirow{2}{*}{$\begin{array}{l}\text { Resto de la provincia } \\
\text { de Pontevedra }\end{array}$} & \multirow{2}{*}{$\begin{array}{c}\text { Resto de las } \\
\text { provincias } \\
\text { gallegas }\end{array}$} & \multirow{2}{*}{$\begin{array}{c}\text { Resto de } \\
\text { Espańa }\end{array}$} & \multirow{2}{*}{ Total } \\
\hline & Pontevedra & Vigo & & & & \\
\hline 1906-1924 & 9 & 15 & 12 & 8 & 2 & 46 \\
\hline$\%$ & 19,56 & 32,61 & 26,09 & 17,39 & 4,35 & 100 \\
\hline
\end{tabular}

Fuentes: elaboración propia a partir de los libros de ingresos de la Inclusa de Pontevedra, 1906-1924, ADP u.i. $14.725 / 3-14.730 / 2$.

Vigo crecía rápidamente desde la década de los ochenta del siglo XIX con una población joven, procedente del éxodo rural, que trabajaba en el cada vez más importante sector industrial y comercial. La ciudad, en 1877, tenía 13.416 habitantes y 96.696 en $1930^{171}$. También en el servicio doméstico trabajaban muchas mujeres jóvenes procedentes de pueblos y aldeas. Si había muchas nodrizas sin retribución residentes en Vigo podemos suponer que es porque bastantes incluseros procedían de esa ciudad, aunque como la mayoría de los ingresos se hacían por el torno no podamos afirmarlo taxativamente, como sí hizo un periódico pontevedrés en su polémica con otro vigués ${ }^{172}$,

Y los números...abonan nuestras afirmaciones con su elocuencia incontrastable. Los datos que obran en la Inclusa, los que se inscriben en el registro civil prueban que los niños acogidos en aquel benéfico asilo SON DE VIGO EL OCHENTA POR CIENTO aproximadamente ${ }^{173}$.

Respecto a las amas sin retribución casadas, sabemos que cuatro de ellas recogieron niños que llevaban su apellido y no el de su esposo ${ }^{174}$, por lo que podría

170 Estudiamos los años 1906, 1909, 1912, 1915, 1918, 1921 y 1924.

171 Velasco Souto, C.F. (2000): 18-19.

172 La polémica surgió entre El Heraldo de Vigo y El Progreso de Pontevedra a raíz del reparto de las subvenciones de la Diputación Provincial a instituciones de ambas ciudades. El periódico pontevedrés afirmaba que el Hospicio era provincial, que beneficiaba a ambas ciudades y que muchos de los allí acogidos eran expósitos que habían nacido en Vigo. "Información errónea”, El Progreso, 875 (8-12-1912), disponible en <http://biblioteca.galiciana.gal>.

173 "Cuestión de números", El Progreso, 877 (11-12-1912), disponible en <http://biblioteca.galiciana.gal>. Las mayúsculas constan en el original.

174 ADP, u.i 14.725/3, 14.726/3, 14.729/1 y 14.730/2. 
tratarse de la recuperación de hijos habidos estando solteras, o bien extramatrimoniales.

Hasta aquí hemos visto, en los años 1906-1924, diversos aspectos de las nodrizas sin retribución que recogían niños de la Inclusa de Pontevedra con sus mismos apellidos. De las que no tenían esta característica podemos decir que más de la mitad, un 52,38\%, estaban casadas y que vivían en una gran proporción en Pontevedra y su término municipal ${ }^{175}$. No podemos establecer si había parentesco entre ellas y los incluseros de los que se hacían cargo, aunque es posible que en algunos casos existiera porque explicaría el hecho de que mujeres muy pobres quisieran cuidar gratuitamente a un expósito. Se entendería así que una sirvienta viuda, mayor de 50 años, recogiera a una asilada de 11 meses, y que sendas mujeres residentes en Madrid y en un pueblo de Ourense se hicieran cargo de una niña de 5 años y de otra de solo unos días de vida, respectivamente ${ }^{176}$.

\subsection{El total de las recuperaciones de los niños de la Inclusa}

De 1906 a 1924 el total de acogidos de la Inclusa de Pontevedra reclamados por sus madres, padres y familiares fue de 50, pero si tenemos también en cuenta a las criaturas entregadas a nodrizas sin retribución con sus mismos apellidos, el número asciende a 96 , es decir, el 8,88\% de los 1.081 menores ingresados ${ }^{177}$, porcentaje que se sitúa en el término medio del de otras inclusas ${ }^{178}$. Aunque pueda parecer bajo, debemos pensar que muchos de los niños que entraron en la Institución en los años citados murieron antes de cumplir el año de vida, por lo que los supervivientes mayores de esa edad fueron solo $616^{179}$. Si sobre ellos calculamos ahora el porcentaje de recuperados, resulta mayor, el 15,58\%. Este porcentaje es notable si consideramos que las personas que recogieron a estos niños eran pobres $y$, en muchos casos, se trataba de mujeres solas. De ahí que la mayoría de los menores recuperados no fueran lactantes y que tuvieran una edad que exigía menos cuidados. El abandono y posterior recuperación podía considerarse como una estrategia de supervivencia, que era ya practicada en el siglo XIX por los familiares de los ingresados en otras inclusas ${ }^{180}$.

175 Hemos tenido en cuenta los años 1903, 1906, 1909, 1912, 1915, 1918, 1921 y 1924. ADP, u.i. $14.725 / 3-14.730 / 2$

176 ADP, u.i. $944,14.729 / 3,14.729 / 1$ y $14.727 / 12$.

177 Hemos tenido en cuenta los ingresos en la Inclusa en los años 1906, 1909, 1912, 1915, 1918, 1921 y 1924. ADP, u.i. 14.725/3-14.730/2.

178 Barba Pérez, M.A. (2017): 558. Valverde Lamsfus, L. (1991): 1.196. Langellotti, A. y TravagliNI, C.M. (1991): 780.

179 ADP, u.i. $14.725 / 3-14.730 / 2$.

180 Costa Cerqueira, A. (2017): 93-94. Rodríguez Martín, A.M. (2009): 168-178. 
El sexo de los menores recogidos presentaba un cierto desnivel, 51,28\% de niños y $48,72 \%$ de niñas, que también se había producido cuando habían ingresado en la Inclusa: $50,79 \%$ niños y $49,21 \%$ niñas ${ }^{181}$.

\section{Conclusiones}

En la Inclusa de Pontevedra la mayoría de los ingresados había sido echada al torno y aunque era posible su posterior recuperación mediante su legitimación o naturalización, se produjeron muy pocos casos. Sin embargo, un porcentaje apreciable de estos niños fue entregado a sus madres, padres o familiares porque la Inclusa, y por extensión la Diputación, facilitó la demostración del parentesco, no realizó investigaciones reservadas sobre la observancia de la moral católica por parte de las personas que reclamaban a estos menores, y solo en una ocasión denegó una entrega. Además, permitió la existencia de las nodrizas sin retribución, 46 de ellas con apellidos iguales a los de la criatura que recogían. La poca documentación que la Inclusa exigía a estas mujeres pone en evidencia de nuevo que la postura de la institución benéfica fue la de no dificultar la reunión de los acogidos con sus madres.

En la Inclusa de Pontevedra, al igual que en otras inclusas españolas, los abandonos fueron numerosos, el porcentaje de niños recuperados fue bajo y la mayoría de las reclamaciones fueron efectuadas por las progenitoras, mayoritariamente solteras. La razón de todo ello era la pobreza generalizada en España, en la época que analizamos, que estaba agravada en el caso de las mujeres por su poca instrucción $y$, si trabajaban fuera de casa, por sus salarios, muy inferiores a los masculinos. La maternidad era un problema más para estas mujeres porque dificultaba o imposibilitaba que continuaran trabajando. Si, además, no tenían leche, conservar el hijo a su lado era una tarea difícil, y más en el caso de las progenitoras solteras, tan abundantes en Galicia. Las leyes de protección a la maternidad aunque se promulgaron a principios del siglo XX, tardaron en ser cumplidas y las casas-cuna y las Gotas de Leche resultaron insuficientes. Las ayudas a la lactancia, que podrían haber sido decisivas para frenar los abandonos, no las concedían todas las inclusas o bien lo hacían de forma muy restrictiva, como la de Pontevedra. Frente a un hijo que no se había deseado o al que era muy difícil cuidar y alimentar, su ingreso en una inclusa se presentaba como una solución pero, por los mismos motivos, su recuperación resultaba poco probable. Incluso, en algunos casos, imposible, dada la alta mortalidad en estos centros benéficos.

181 Tenemos en cuenta a los ingresados en 1909, 1909, 1912, 1915, 1918, 1921 y 1924. ADP, u.i. $14.725 / 3-14.730 / 2$. 
La pobreza de las madres y de los pocos padres que recuperaban a sus niños en la Inclusa de Pontevedra quedaba ya demostrada en las circunstancias que rodeaban el ingreso de estos menores echados al torno, porque iban envueltos en trapos o ropas viejas y las notas que muchas veces llevaban evidenciaban la poca instrucción de sus progenitoras. Estos trozos de papel contenían la explicación del motivo del abandono, y no era el deshonor sino siempre la pobreza, unida muchas veces a la enfermedad o la muerte de la madre, o a la imposibilidad de cuidar a su hijo. Esta pobreza la vemos también reflejada en el hecho de que la mayoría de los niños recuperados estaban ya destetados, por lo que ya no necesitaban tantos cuidados ni una nodriza que, dada la falta de recursos de las progenitoras, no podrían pagar.

También se produjeron pocas recuperaciones de los hijos legítimos y naturales admitidos en la Inclusa tras el visto bueno de la Diputación. La causa está en los motivos que habían justificado su ingreso. Todos ellos eran tan graves, y en algunos casos permanentes, como la muerte de la madre, que dificultaban la posterior reclamación del menor. 


\section{BibliografíA}

Alonso Álvarez, L. (2005): "La crisis de la economía tradicional: continuidad y cambio en la Galicia del siglo XIX”, en Juana, J. de y Prada, J. (coords.): Historia contemporánea de Galicia, Madrid, Ariel: 33-55.

Álvarez Novoa, R. (1930): "La benéfica institución de la Gota de Leche”, en Cao Mora, J.: Libro de Oro de la Provincia, Vigo, edición a cargo del autor: 155-156.

Amo del Amo, M. C. (2008): La familia y el trabajo femenino en España durante la segunda mitad del siglo XIX, tesis doctoral, Universidad Complutense de Madrid, disponible en 〈https://eprints.ucm.es/8148/1/T30558.pdf〉.

Amo del Amo, M. C. (2009): "La educación de las mujeres en España: de la amiga a la Universidad”, Participación educativa, 11: 8-22, disponible en 〈www.mecd.gob.es/ revista-cee/pdf/n11-amo-amo.pdf $>$.

Arenal, C. (1974): “El trabajo de las mujeres”, en Armiño, M. (ed.): La emancipación de la mujer en España, Madrid, Júcar: 81-95.

Arenal, C. (28-8-1902): “Cartas a un obrero”, El Áncora, 1.463.

Ballarín Domingo, P. (2001): La educación de las mujeres en la España contemporánea, Madrid, Síntesis.

Barba Pérez, M. A. (2017): La alimentación y cuidados en los lactantes en el Hospicio provincial de Valladolid, tesis doctoral, Universidad de Valladolid, disponible en <http://uvadoc.uva.es/handle/10324/27671'.

Benso Calvo, C. y Cid Galante, R. M. (2011a): "As conquistas femininas na Galicia do primeiro terzo do século XX”, en Juana López, J. de y Prada Rodríguez, J. (dirs.): As mulleres en Galicia no século XX, Vigo, Ir Indo Edicións: 47-82.

Benso Calvo, C. y Cid Galante, R. M. (2011b): Entre a tradición e o cambio en Galicia: as mulleres na sociedade ourensá de comezos do século XX, Ourense, Deputación Provincial.

Bock, G. (2000): "Pobreza femenina, derechos de las madres y Estado del bienestar (1890-1950)”, en Duby, G. y Perrot, M. (dirs.): Historia de las mujeres en Occidente, vol. 5, Madrid, Taurus: 438-478.

Borderías, C. y Pérez-Fuentes, P. (2009): "Mujeres, trabajos y economías familiares (siglos XIX y XX)”, en Borderías, C. (ed.): Historia de las mujeres: perspectivas actuales, Barcelona, Icaria: 269-308.

Bouzón Gallego, A. (2001): "El Hospital de pobres y peregrinos de la ciudad de Tui", Memoria Ecclesiae, 18: 349-367.

Cámara Álvarez, M. de la (1975): Reflexiones sobre la filiación ilegítima en el Derecho Espanol, Madrid, Tecnos.

Capel Martínez, R. M. (1986): "Mujer y trabajo en la España de Alfonso XIII”, en VV.AA.: Mujer y sociedad en España, 1700-1975, Madrid, Ministerio de Cultura: 207-238. 
Castro, X. (2007): Servir era o pan do demo: Historia da vida cotiá en Galicia: séculos XIX e XX, Vigo, Nigratea.

Código Civil español (1889): Madrid, Centro Editorial Góngora.

Consejo Superior de Protección a la Infancia (1908): Leyes y disposiciones vigentes de Protección a la Infancia, Madrid, Imprenta del Asilo de Huérfanos.

Costa Cerqueira, A. (2017): "Assistência, pobreza e institucionalizaçao infantil: usos estratégicos da roda dos expostos da Santa Casa da Misericórdia (Salvador, século XIX)", História e Cultura, 6 (2): 81-100, disponible en <https://dialnet.unirioja.es/ servlet/articulo?codigo $=6118074>$.

Espuny Tomás, M. J. (2010): “El descanso puerperal y su cumplimiento”, en Franco Rubio, G. (ed.): Debates sobre la maternidad desde una perspectiva histórica (siglos XVI-XX), Barcelona, Icaria: 189-205.

Flecha García, C. (1996): Las primeras universitarias en España, Madrid, Narcea.

Freire Lestón, X. V. (1992): "Aproximacions a un estudio da vida cotiá da muller labrega na Galicia contemporánea (1868-1930)”, Grial, 115: 418-429.

Fuchs, R. G. (2003): "Beneficencia y bienestar”, en Kertzer, D.I. y Barbagli, M. (comps.): Historia de la familia europea. Vol. II, Barcelona, Paidós Ibérica: 243-296.

García Alcalde, P. (1991): "Una institución benéfica municipal riojana. La Casa Cuna del Niño Jesús”, Berceo, 120: 117-123.

Garnelo Mariñas, E. (1988): “La Inclusa provincial de Pontevedra, 1872-189”, Pontevedra. Revista de estudios provincias, 4: 143-152.

Guia general de la provincia de Pontevedra (1894): Pontevedra, La Teucrina.

Junta Provincial de Beneficencia de Pontevedra (1925): Memoria, Pontevedra, imprenta de Julio Antúnez.

Junta Provincial de Beneficencia de Pontevedra (1926): Memoria, Pontevedra, imprenta de Celestino Peón.

Knibiehler, Y. (2000): “Cuerpos y corazones", en Duby, G. y Perrot, M. (dirs.): Historia de las mujeres en Occidente, vol. 4, Madrid, Taurus: 339-388.

Langellotti, A. y Travaglini, C. M. (1991): "L'infanzia abbandonata nel Viterbese (sec. XVIII-XX)”, en Enfance abandonnée et société en Europe, XIV-XX siècle, Roma, École Française de Roma: 741-784.

Laplaige, D. (1989): Sans famille à Paris: orphelins et enfants abandonnés de la Seine au XIXe siècle, Paris, Centurion.

Mateo Álvarez, J. L. (2002): O ex-convento de San Francisco de Vigo, Vigo, Concellería de Patrimonio histórico del Concello de Vigo.

Maza Zorrilla, E. (1987): Pobreza y asistencia social en España, siglos XVI al XX, Valladolid, Universidad de Valladolid.

Maza Zorrilla, E. (1999): Pobreza y beneficencia en la España contemporánea, Barcelona, Ariel. 
Montero García, F. (1994): "De la Beneficencia a la reforma social. Los orígenes de la política social del Estado: estado de la cuestión, fuentes”, Espacio, tiempo y forma, serie $V, 7: 415-434$.

Morata Marco, E. M. (2010): "Miradas femeninas sobre la maternidad. Discursos de las mujeres españolas en el cambio del siglo XIX al XX”, en Franco Rubio, G. (ed.): Debates sobre la maternidad desde una perspectiva histórica (siglos XVI-XX), Barcelona, Icaria: 345-368.

Muñoz Abeledo, L. (2012): “Actividad femenina en industrias pesqueras de España y Portugal (1870-1930)", Historia Contemporánea, 44: 49-71, disponible en <www. ehu.eus/ojs/index.php/HC/article/viewFile/pdf/6602/6040>.

Nash, M. (1994): "Experiencia y aprendizaje: la formación histórica de los feminismos en España”, Historia Social, 20: 151-172.

Nash, M. (2000): "Maternidad, maternología y reforma eugénica en España. 19001939”, en Duby, G. y Perrot, M. (dirs.): Historia de las mujeres en Occidente, vol. 5, Madrid, Taurus: 687-708.

Nash, M. (2010): “Maternidades y construcción identitaria: debates del siglo XX”, en Franco Rubio, G. (ed.): Debates sobre la maternidad desde una perspectiva bistórica (siglos $X V I-X X)$, Barcelona, Icaria: 23-49.

Nielfa Cristóbal, G. (2004): "Hombres y mujeres ante la reforma social”, en Palacio Morena, J.I. (coord.): La Reforma social en España: en el centenario del Instituto de Reformas Sociales, Madrid, CES: 129-147.

Palacio Morena, J. I. (2004): La construcción del Estado social: en el centenario del Instituto de Reformas Sociales, Madrid, CES.

Pernas Oroza, H. (2011): Historia das mulleres en Galicia. Época contemporánea, Baiona, Xunta de Galicia y Nigratea.

Puig y Alfonso, F. (1927): Beneficencia: artículos, conferencias, informes, memorias, comunicaciones, ponencias, Barcelona, Casa Provincial de Caridad.

Reglamento. Casa Provincial de Maternidad y Expósitos de Barcelona (1894): Barcelona, Imprenta de la Casa Provincial de Caridad.

Reglamento de la Casa de Maternidad y Espósitos de la provincia de Lugo: aprobado por Real Orden de 18 de Mayo de 1863 (1883): Lugo, Imprenta de Soto Freire.

Reglamento provisional para el servicio de socorro a niños en lactancia (1916): Pontevedra, Junta Superior de Protección a la Infancia y represión de la mendicidad.

Revuelta Eugercios, B. (2011): Los usos de la inclusa de Madrid, mortalidad y retorno a principios del siglo $X X$, tesis doctoral, Universidad Complutense de Madrid, disponible en <https://eprints.ucm.es/13772/1/T33310.pdf>.

Rodríguez Galdo, M. X. (1986): “A economía en Galicia no século XIX”, en Juana, J. de y Castro, X. (dirs.): II Xornadas de Historia de Galicia. Aspectos da realidade galega (séc. XVI ó XX), Ourense, Deputación Provincial: 109-134. 
Rodríguez Labandeira, J. (1994): "El trabajo de la mujer en el campo a comienzos del siglo XX”, en VV.AA.: Ordenamiento jurídico y realidad social de las mujeres, Madrid, Universidad Autónoma: 259-266.

Rodríguez Martín, A. M. (2003): “La Inclusa de Pontevedra, 1872-1903”, Pontevedra, Revista de estudios provinciais, 19:179-204.

Rodríguez Martín, A. M. (2007): "Una estrategia de supervivencia femenina: las nodrizas sin retribución de la Inclusa de Pontevedra, 1872-1903”, Minius, 15: 239-253.

Rodríguez Martín, A. M. (2008): "El destino de los niños de la Inclusa de Pontevedra, 1872-1903", Cuadernos de Estudios Gallegos, 121: 353-388.

Rodríguez Martín, A. M. (2009): "Una estrategia de supervivencia familiar en Barcelona, en la segunda mitad del siglo XIX”, en Gonzalvo Aizpuru, P. (coord.): Familia y relaciones diferenciales: género y edad, Murcia, Universidad de Murcia: 167-183.

Rodríguez Martín, A. M. (2010): "Las Casas de Maternidad en España en la segunda mitad del siglo XIX. El caso de Zaragoza”, en Franco Rubio, G. (ed.): Debates sobre la maternidad desde una perspectiva histórica (siglos XVI-XX), Barcelona, Icaria: 165-187.

Rodríguez Martín, A. M. (2015): “El Hospicio de Pontevedra, 1853-1903”, Pontevedra. Revista de estudos, 24: 123-191.

Rollet, C. (2001): Les enfants an XIX siècle, Paris, Hachette.

Sanglard, G. (2016): "Entre o Hospital Geral e a Casa dos Expostos: assistência à infancia e transformaçao dos espaços da Misericórdia carioca (Rio de Janeiro, 18701920)", Revista Portuguesa de História, 47: 337-358, disponible en <http://hdl. handle.net/10316.2/40695>.

Trinidad Fernández, P. (1990): “Trabajo y pobreza en la primera industrialización”, en VV.AA.: Historia de la acción social pública en España. Beneficencia y previsión, Madrid, Ministerio de Trabajo y Seguridad Social: 101-135.

Valiente Hernández, C. (1996): “¿Cuán fecundo es el feminismo? Las políticas públicas para la mujer trabajadora en España durante la Dictadura de Primo de Rivera?”, en: El trabajo de las mujeres, pasado y presente. Actas del Congreso Internacional del Seminario de Estudios Interdisciplinarios de la Mujer, vol. IV, Málaga, Diputación Provincial: 5573.

Valverde Lamsfus, L. (1991): "Legitimidad e ilegitimidad. Evolución de las modalidades de ingreso en la Inclusa de Pamplona, 1740-1934”, en VV.AA.: Enfance abandonnée et société en Europe, XIV-XX siècle, Roma, École Française de Roma: 1.169-1.197.

Varela Iglesias, M. (2013): Educación institucional y sociedad en Vigo en el siglo XIX, tesis doctoral, Universidad de Santiago de Compostela, disponible en $\langle\underline{\mathrm{http}: / / h d l . h a n d-}$ le.net/10347/9291>.

Vázquez Ramil, R. (2012): "Las mujeres gallegas y la Institución Libre de Enseñanza: de Concepción Arenal a las universitarias de la Residencia de Señoritas”, en González 
Fernández, M. et altri (eds.): As mulleres na Historia de Galicia, Santiago de Compostela, Andavira Editora: 165-196.

Velasco Souto, C. F. (2000): Galiza na II República, Vigo, A Nosa Terra.

Vilar Rodríguez, M. (2007): “¿Entre la limosna y el bienestar? Origen, desarrollo y consecuencias de las políticas sociales en Galicia (1890-1935)”, Cuadernos de Historia Contemporánea, 29: 173-197.

\section{Fuentes}

Archivo de la Diputación de Pontevedra

Unidad de instalación: 941, 943, 944, 961, 962, 975, 977, 984, 986, 13.033-13.036, $13.038,13.040,13.045,13.151-13.155,13.157,13.158,13.160,13.161,14.721 / 1-$ $14.731 / 1,14.740 / 1-2$ y $17.741 / 1-2$. 
